\title{
Ex-day Returns of Stock Distributions: An Anchoring Explanation
}

\begin{abstract}
We offer a new anchoring explanation for the ex-day abnormal returns of stock distributions including stock dividend distributions, splits, and reverse splits. We propose that investors tend to anchor on cum-day prices in valuating ex-distribution stocks, resulting in a positive association between ex-day returns and adjustment factors. We find that this positive return-factor relation exists for all three types of stock distributions and in both the pre- and post-decimalization periods. Furthermore, we find that this positive return-factor relation is more pronounced among events that are more subject to investors' anchoring propensity, featured by less investor attention, greater arbitrage difficulty, greater valuation uncertainty, less investor sophistication, and higher market sentiment. Lastly, using brokerage account data, we show that stocks that are traded by investors with more investment experience demonstrate a weaker return-factor relation.
\end{abstract}

Keywords: Economics: Behavior and Behavioral Decision Making; Finance: Asset pricing; Anchoring; Splits; Stock Dividends

JEL classification: G02, G12, G14 


\section{Introduction}

Stock distributions, including stock dividend payments, splits, and reverse splits, are cosmetic accounting changes without real impact on business operations. Nontrivial abnormal returns on the ex-distribution days of stock distributions (Grinblatt et al. 1984) are puzzling as stock distributions contain no new information and are typically tax-exempt. Existing explanations are mainly based on microstructure theories such as order imbalance and bid-ask bounce (Conrad and Conroy 1994), bid-ask spread (Frank and Jagannathan 1998), price discreteness (Bali and Hite 1998), and when-issued trading (Nayar and Rozeff 2001).

In this study, we propose a new explanation that the puzzling returns on the ex-distribution days of the stock distributions are partially attributable to investors' anchoring bias (Tversky and Kahneman 1974). In the 1960s, the Committee on Accounting Procedure stated that "many recipients of stock dividends look upon them as distributions of corporate earnings and usually in an amount equivalent to the fair value of the additional shares received." This observation suggests that market participants view stock dividends as valuable as pre-distribution stocks and fail to adjust valuation sufficiently by stock distributions. To put it differently, investors may anchor on the cum-day price in valuating ex-distribution stocks, which biases the ex-day price toward the cum-day price and contributes to the puzzling ex-day returns.

We extend the above argument and develop a unified anchoring model that is applicable to stock dividend distributions, splits, and reverse splits. Consistent with Lopes (1985), we model the ex-day valuation as a weighted average of the cum-day price (the anchor) and the rational ex-day price (the target) with a nonnegative weight (the anchoring propensity) attached to the anchor. The model generates three predictions. First, the sign of the adjustment factor determines the relative position of the anchor, and therefore, the sign of the ex-day return. For stock dividend distributions and splits, the cum-day price is an upward-biased anchor that inflates the expectation of ex-day price, thus resulting in a positive ex-day return. For reverse splits, the cum-day price acts as a downward-biased anchor that induces a negative ex-day return. Second, if investors at least partially anchor on the cum-day price and fail to fully adjust 
valuation by the stock distribution, the ex-day return will be positively associated with the adjustment factor. This positive return-factor relation is termed the first-order anchoring effect. Third, the investors' anchoring propensity differs across events. The positive relation between ex-day returns and adjustment factors, which results from the first-order anchoring effect, is more pronounced among events that are more subject to investors' anchoring propensity. The influence of the investors' anchoring propensity over the return-factor relation is termed the moderating effect.

We utilize a large U.S. stock distribution sample spanning 1929 to 2015 to test the three predictions of our anchoring model. First, we follow Grinblatt et al. (1984) and Woolridge and Chambers (1983) to calculate the average abnormal returns by event type. In our sample, the average ex-day abnormal returns are $1.50 \%$ for stock dividend distributions, $1.10 \%$ for splits, and $-4.55 \%$ for reverse splits, and the magnitude of the returns is comparable to those in the prior literature. This evidence supports the first model prediction that the sign of the adjustment factor determines the sign of the ex-day returns.

Our second model prediction is that the ex-day abnormal return is positively associated with the adjustment factor. In the empirical tests, we first sort distribution events into groups based on the magnitude of the adjustment factors and find a positive correlation between returns and factors across the groups. In the formal test, we regress the ex-day abnormal return on the adjustment factor in a cross-section of the stock distribution events and find a significantly positive coefficient of the adjustment factor. The result indicates that higher adjustment factors induce higher ex-day abnormal returns, thus supporting the first-order anchoring effect. We also examine the return-factor relation in the subsamples of stock dividend distributions, splits, and reverse splits, and the positive return-factor relation holds in all three types of distributions. We further conduct sub-period tests before and after decimalization in 2001, and the positive return-factor relation remains significant in both sub-periods. This finding suggests that even in the post-decimalization period when transaction costs are substantially reduced, investors' anchoring bias still plays a role in affecting the ex-day stock returns.

The third model prediction is that the anchoring effect is more evident when the investors' anchoring propensity is greater. Accordingly, we explore how the event-varying anchoring propensity moderates the 
documented positive return-factor relation. We capture investors' anchoring propensity from five perspectives: investors' attention, arbitrage difficulty, valuation uncertainty, investor sophistication, and market sentiment.

First, we argue that more investors' attention to the distribution event reduces the weight attached to the anchor and thus leads to a lower anchoring propensity. Our first measure of investors' attention is the salience of the distribution events. A salient stock distribution, such as a 2-for-1 split, arguably attracts more attention compared to a 5\% stock dividend. Thus, the investors' anchoring propensity is expected to be low among salient events. We further use the number of public earnings announcements on the ex-day to measure the distraction effect (Hirshleifer et al. 2009). Earnings disclosure is one of the most important sources of news in the financial markets that competes for investors' limited attention. When more firms disclose their earnings on the ex-day, market participants are expected to pay less attention to the distribution events and thus demonstrate a greater anchoring propensity.

Second, arbitrageurs avoid trading stocks with greater arbitrage difficulties, which are featured by higher bid-ask spreads (Shleifer and Vishny 1997) and/or higher idiosyncratic volatility (Pontiff 2006). Hence, these stocks are expected to be more affected by the anchoring bias. Third, literature suggests that stocks with greater valuation uncertainty, such as younger stocks with limited past records, are more affected by investors' psychological biases (e.g., Baker and Wurgler (2006), Kumar (2009a)). We therefore expect the anchoring effect to be stronger among younger stocks.

Fourth, a stock is expected to be more affected by the anchoring bias when investors trading the stock are less sophisticated on average. We measure investor sophistication using institutional ownership and a bunch of stock characteristics that have been documented in the literature to be associated with the preference of unsophisticated individual investors. Stocks that are heavily traded by individual investors are expected to exhibit a stronger anchoring effect. Lastly, noise traders participate more actively in the stock markets following higher market sentiment (Yu and Yuan 2011). In such circumstances, the cognitive biases of investors such as anchoring is expected to exert a greater influence on asset prices. 
We corroborate tests of the moderating effect by constructing additional anchoring propensity measures based on account-level data from a large U.S. discount brokerage house, which have been widely used to investigate retail trading and preference (e.g., Barber and Odean (2000), Kumar (2009b)). This dataset contains monthly portfolio positions of a set of individual investors from 1991 to 1996 . For each event stock, we calculate its aggregate weight in the portfolios of the individual investors of the brokerage house in excess of its weight in the market portfolio. A higher excess weight indicates that the stock is invested disproportionally more by individual investors and thus should be more affected by the anchoring bias. We also construct three direct measures of investors' investment experience based on previous studies (e.g., Barber and Odean (2000), Dhar and Zhu (2006)): the average portfolio size of the investors, average number of years that investors have opened their accounts with the brokerage house, and average number of trades that they have executed before. We expect experienced investors to be less affected by the anchoring bias and thus stocks largely traded by such sophisticated individual investors to exhibit a weaker anchoring effect.

The cross-sectional regression results show that the positive relation between the ex-day return and the adjustment factor is stronger when the investors' anchoring propensity is greater. Specifically, the positive return-factor relation is more evident when the distribution events are less salient or more firms disclose earnings on the ex-day. It is stronger for stocks with higher bid-ask spreads, higher idiosyncratic volatility, shorter listing history, lower prices, or lower institutional ownership, and is stronger following higher market sentiment. Tests based on measures developed from the brokerage account data show that the positive return-factor relation is stronger among stocks with higher excess retail investments or heavily traded by investors with less investment experience. These findings provide support for the moderating effect that the strength of the first-order anchoring effect is conditional upon investors' anchoring propensity.

In all of the cross-sectional regressions, we control for a set of stock characteristics including the stock price level, pre-event returns, changes in turnover, Nasdaq indicator, and time trend. In the robustness checks, we further control for the bid-ask spread, bid-ask bounce measured by a location 
parameter (Conrad and Conroy 1994), and rounding return due to price discreteness (Bali and Hite 1998). The results remain even with a smaller sample size due to the unavailability of these control variables.

Our paper contributes to the literature in three ways. First, it offers a novel explanation for the puzzling ex-day returns of stock distributions in addition to the traditional microstructure explanations. Second, our paper adds both theoretical and empirical evidence to the burgeoning literature on the impact of investors' anchoring bias on the financial markets. Our anchoring model could be applied to other corporate events, like cash dividend payments, seasoned equity offerings, mergers and acquisitions (Baker et al. 2012), and cross-listings (Chang et al. 2013). Third, by utilizing a special setting in which anchoring is highly likely to be elicited, we explore the initiation of the anchoring process and the impact of the moderator variables. This study thus adds to the work on the anchoring effect in the experimental psychology literature, which is a deep-rooted yet puzzling psychological bias.

\section{Literature Review}

\subsection{Ex-Day Returns of Stock Distributions}

In an efficient market, stock distributions should only be cosmetic and do not directly affect firms' future operating cash flow and values. However, previous studies find nontrivial returns on both announcement and ex-distribution days. Researchers generally agree that the announcement return is attributable to the inside information signaled by stock distributions (Lakonishok and Lev 1987). However, the ex-distribution return, with a magnitude comparable to the announcement return, is puzzling because distribution events are known in advance and contain no new information. Grinblatt et al. (1984) report that the ex-day returns are $2.82 \%$ and $1.96 \%$ on average for pure stock dividends and pure splits, respectively. Woolridge and Chambers (1983) find an average ex-day return of $-2.09 \%$ for reverse splits. These findings are bewildering as the theories applicable to cash dividends, such as differential tax brackets (Elton and Gruber 1970) and dividend capturing (Karpoff and Walkling 1990), do not apply to stock distributions that are typically tax-free. 


\subsection{Anchoring Bias}

In the seminal study of Tversky and Kahneman (1974), subjects are asked to estimate the percentage of African countries in the United Nations. A random number is generated from a wheel of fortune in their presence. They are asked to compare their estimate with the wheel number and then determine the precise estimate. The experiment results show that estimates are biased towards the wheel number. Tversky and Kahneman (1974) argue that to form a numerical estimate, participants tend to begin from a reference point or an anchor, even for the totally uninformative wheel number in the example, and then make directional adjustment that is usually insufficient.

Follow-up studies show that anchoring influences people's decision-making processes in various occasions. Studies on the impact of anchoring in economic activities, while embryonic, are on the rise. For example, anchoring is useful in negotiation (Galinsky and Mussweiler 2001) in which the first offer price is a strong predictor of the final settlement price. Anchoring might also drive money illusion (Shafir et al. 1997) that people often mix prices and returns in both nominal and real terms and are biased towards the nominal evaluations. Consistently, Genesove and Mayer (2001) show that real estate sellers anchor on the historical nominal purchase price and are averse to realizing nominal losses. Lambson et al. (2004) further show that out-of-town buyers anchor on their home-state prices; if they come from a state with higher-price real estate, they tend to offer a higher premium for this purchase. Beggs and Graddy (2009) find an anchoring bias in art auctions. The real estate market and art auctions both feature high valuation uncertainty. Tversky and Kahneman (1974) assert that greater ambiguity in the value of a commodity results in increased importance of anchoring in the determination of its price. Northcraft and Neale (1987) document that even real-estate experts with abundant information suffer from the anchoring bias.

In the financial markets, Hirshleifer (2001) argues that stocks with greater valuation uncertainty are more likely to be affected by psychological biases. Campbell and Sharpe (2009) find that consensus economic forecasts made by experts are biased towards the release values in previous months. Cen et al. (2013) document that analysts tend to anchor on industry norms in making earnings forecasts. George and Hwang (2004) propose that investors anchor on the 52-week high and underreact to good news as prices 
approach the 52-week high. Baker et al. (2012) reveal that parties in merger and acquisition activities tend to anchor on the recent 52-week high to simplify the valuation and negotiation process. Chang et al. (2013) find that in cross-listings, participants anchor on the price of the existing class of shares in valuating new shares. Dougal et al. (2015) show that anchoring influences the borrowing rate of bank loans.

Based on the aforementioned studies, we propose a new explanation for the puzzling ex-day returns of stock distributions. We argue that the ex-day returns are partially attributable to investors' anchoring bias. We are predominantly interested in the anchoring effect in the particular scenario of ex-day valuation because the anchor is unambiguously the cum-day price.

\subsection{Microstructure Explanations}

Stock splits have been investigated extensively in the literature, and the existing explanations for the ex-day returns of splits are mainly based on the market microstructure theories. Maloney and Mulherin (1992) posit that splits bring stock prices back to an optimal trading range and result in enlarged shareholder bases. Thus, a large number of buyer-initiated orders results in a bid-ask bounce on the ex-day, leading to a positive ex-day return. Assuming most transactions as single or small round-lot orders, Conrad and Conroy (1994) argue that the ex-day orders of splitting stocks consist of a higher number of small post-split buy-orders relative to that of pre-split sell-orders. The mismatched order size also drives a buy-order imbalance and a positive ex-day return. Although the order imbalance might explain the ex-day returns of splits, it lacks explanatory power for stock dividends. Due to the relatively small distribution ratio of stock dividends, the additional buy-orders on the ex-day are only marginal as predicted by either the enlarged shareholder base or mismatched order-size hypothesis.

After the record date of splits, shares can be traded on a when-issued basis until the splits are effective. Nayar and Rozeff (2001) argue that investors prefer to buy post-split stocks from the when-issued market to avoid trading inconvenience, particularly when the splits create odd lots. As the ex-day return is measured relative to the cum-day price, the when-issued premium positively contributes to the ex-day return. However, this theory cannot explain the puzzling ex-day returns for stock dividends, 
as when-issued trading is typically unavailable for stock dividends. Bali and Hite (1998) posit that because of price discreteness, ex-day price that is not a tick multiple is rounded up, resulting in an ex-day return that increases with the magnitude of the dividend and tick size. However, Graham et al. (2003) find contradicting evidence that ex-day returns are higher in eras with finer ticks.

Moreover, the evidence is mixed with regard to the changes in shareholder composition and liquidity around stock distributions. Lamoureux and Poon (1987) find an increased number of shareholders, a larger number of trades, lower trading volume, and smaller average trade size after splits, which suggest that the number of small investors increases post splits. However, Maloney and Mulherin (1992) find an increased number of institutional shareholders and a higher institutional ownership after splits. Easley et al. (2001) find increased unformed trades after splits, which indicates that splits attract small (uninformed) investors.

In sum, the existing explanations of ex-day returns for splits in the microstructure literature are not coherent or conclusive. This motivates us to develop a simple but unified anchoring model that could be applicable to all three types of distribution events.

\section{Anchoring Framework}

We present a simplified model to illustrate how anchoring affects the ex-day returns in a perfect market without microstructural frictions. In the absence of new information on the ex-day of stock distributions, the rational price is expected to be

$$
P_{\mathrm{ex}}^{R}=\frac{P_{\text {cum }}}{1+\text { factor }},
$$

where the superscript $R$ denotes the rational price, and the subscripts ex and cum denote ex-day and cum-day closing prices, respectively. We omit the expectation operator throughout this section with a slight abuse of notation. The variable factor is the adjustment factor and takes values on support $(-1,+\infty)$. It is positive for splits and stock dividend distributions. For example, factor is 0.05 for a $5 \%$ stock dividend, and the rational ex-day price equals the cum-day price over 1.05 . It is one for a 2 -for-1 
split such that the rational ex-day price is half of the cum-day price. factor is negative for reverse splits. For example, factor equals -0.5 for a 1 -for-2 reverse split and the ex-day price should be twice the cum-day price.

Following Tversky and Kahneman (1974) and Lopes (1985), we model the anchored ex-day price as a weighted average of the cum-day price (the anchor) and the rational ex-day price (the target). The anchored ex-day price is

$$
P_{e x}^{A}=\gamma P_{c u m}+(1-\gamma) P_{e x}^{R},
$$

where the superscript $A$ denotes the anchored price. The anchoring propensity $\gamma$ takes values on support [0,1], with a higher $\gamma$ indicating a higher weight attached to the anchor, and therefore, a greater investors' anchoring propensity. At one extreme where $\gamma=0$, investors are immune to anchoring such that $P_{E x}^{A}=P_{E x}^{R}$. At the other extreme where $\gamma=1$, investors completely anchor on the cum-day price at face value and make no adjustment for stock distributions.

Substituting (1) into (2), we have

$$
P_{e x}^{A}=\frac{1+\gamma \times \text { factor }}{1+\text { factor }} P_{\text {cum }}
$$

Rearranging Equation (3), the ex-day return $r$ is

$$
r=\frac{P_{e x}^{A}}{P_{e x}^{R}}-1=\gamma \times \text { factor }
$$

Equation (4) has three predictions. First, with anchoring taking effect (positive $\gamma$ ), the sign of factor determines the sign of the ex-day return $r$. If factor $\geq 0, P_{E x}^{A} \geq P_{E x}^{R}$ and $r \geq 0$. If factor $<0, P_{E x}^{A}<P_{E x}^{R}$ and $r<0$. This sign prediction implies that for splits and stock dividend distributions, anchoring induces an upward bias for ex-day valuation, resulting in a positive ex-day return. The intuition behind is straightforward. A positive adjustment factor makes a stock appear to be traded at a discount on the ex-day. Investors who are anchored by the cum-day price are attracted to buy the seemingly cheap stock and push up the ex-day price, which results in a positive ex-day return. For reverse splits, anchoring 
exerts a downward bias on price, and induces anchored investors to sell the stock, which results in a negative ex-day return.

The second prediction is a positive relation between the ex-day return and the adjustment factor. In an extreme case where $\gamma=1, r=$ factor. The adjustment factor thus sets a cap for the anchoring component of the ex-day return, which is achieved when investors are subject to the greatest amount of the anchoring bias by completely ignoring the distribution events. In most cases, investors would not entirely ignore the distribution events and attach $100 \%$ weight to the anchor, thus $\gamma$ is typically less than unity. As long as investors more or less suffer from the anchoring bias, $\gamma$ will be greater than zero. This reasoning predicts a positive association between the ex-day return and the adjustment factor in the cross-sectional regression, which is termed the first-order anchoring effect.

The third prediction focuses on investors' anchoring propensity $\gamma$, which is a moderator variable that influences the ex-day return through its interaction with the adjustment factor. If the anchoring propensity is greater as indicated by a higher $\gamma$, the return-factor relation will be more positive. The event-varying anchoring propensity helps to explain why investors demonstrate different degrees of anchoring bias in different scenarios. Furthermore, the anchoring propensity explains why the ex-day returns vary for events with the same adjustment factors. The influence of investors' anchoring propensity over the return-factor relation is termed the moderating effect, which is discussed in detail in Section 5.

\section{Anchoring Effect}

\subsection{Data}

We include all stock distribution events from the Center for Research in Security Prices (CRSP) daily event dataset from 1926 to 2015, with an event code of 5523 (for splits and reverse splits) or 5533 (for stock dividend distributions). We eliminate observations with concurrent events if the same firm announces any stock or cash distribution, executes any other distribution, or announces quarterly earnings on the ex-day. We collect daily stock prices and returns from CRSP and the financial statement data from 
COMPUSTAT. We obtain institutional holding data from 13F filings of Thomson Reuters from 1978 to 2015. We also use the brokerage account data of Barber and Odean (2000), which contain the portfolio holdings of individual investors in a large U.S. discount brokerage house spanning 1991 to $1996 .^{1}$

\subsection{Event Returns}

Table 1 reports the descriptive statistics for event returns grouped by the type of distribution event. We follow Grinblatt et al. (1984) to categorize events with a positive adjustment factor lower than 0.25 as "stock dividend distribution" and those with an adjustment factor equal to or higher than 0.25 as "split." We winsorize returns at the top and bottom one percentiles to reduce the impact of outliers. Panels A and B report the raw returns and Carhart (1997) four-factor adjusted abnormal returns on the ex-days, respectively. ${ }^{2}$ As the average of the abnormal returns is close to that of the raw returns, we focus on the abnormal returns in the following analyses. Panel B shows that the average of the ex-day abnormal return is $1.50 \%$ for 9,695 stock dividend distributions and $1.10 \%$ for 17,868 splits, and both numbers are significantly positive. For the 3,044 reverse splits, the average of the abnormal return is $-4.55 \%$ and significantly negative. The magnitude of the ex-day abnormal returns is comparable to that in Grinblatt et al. (1984) and Woolridge and Chambers (1983). The pattern is similar for the median of ex-day abnormal

${ }^{1}$ We sincerely thank Terrance Odean for making this account data available to us.

${ }^{2}$ To estimate the factor loadings, we follow the methodology of Graham et al. (2003) and regress monthly stock returns on Carhart four factors over the prior 60 months. We eliminate events with fewer than 24 months of returns in the estimation window. In the robustness tests, we calculate market-adjusted returns, market model-adjusted returns, and Fama-French three factor-adjusted returns, and estimate the four-factor models using daily stock returns in the prior one-year window. The magnitude and significance level of abnormal returns from the alternative risk adjustment methods are qualitatively unchanged. We do not report these results for the sake of brevity. 
returns by event type. These results are consistent with findings in prior studies. More importantly, the results provide support for the sign prediction of our anchoring model.

\section{(Insert Table 1 here.)}

Many studies (e.g., Graham et al. (2003), Chung et al. (2004)) show that the transaction costs are substantially reduced in the post-decimalization period, which could result in a stronger arbitrage force after 2001. To examine whether our anchoring hypothesis still holds after decimalization, we report the average ex-day abnormal returns after 2001 in Panel C of Table 1. The result shows that even in the post-decimalization era, the ex-day returns for stock dividend distributions remain at a similar level. The average abnormal return is significantly positive with a magnitude of $1.51 \%$ for 799 stock dividend distributions. Although the average abnormal return for splits drops from $0.92 \%$ in the whole period to $0.31 \%$ in the post-2001 period for 1,995 events, it is still significantly positive. The average abnormal return is $-1.99 \%$ for 1,156 reverse splits and remains significantly negative. In short, the sign prediction of our anchoring model is still supported even in the post-decimalization era.

To directly control for the influence of the microstructure effect (Conrad and Conroy 1994, Maloney and Mulherin 1992), we calculate the ex-day abnormal returns based on the closing bid-to-bid prices and report the statistics in Panel D of Table $1 .^{3}$ A comparison of Panels D and B reveals that the average of the bid-to-bid returns is smaller but still significantly positive for splits. For stock dividend distributions and reverse splits, both the economic magnitude and statistical significance of bid-to-bid returns are similar to that of close-to-close returns. The results support our conjecture in Section 2.3 that the bid-ask bounce might partially explain the ex-day returns of splits but lacks explanatory power for stock dividend

${ }^{3}$ Continuous data of closing bids are available for NYSE and AMEX stocks only after 28 December 1992, which reduces the number of observations. 
distributions. Overall, the results based on bid-to-bid returns still support the first prediction of our anchoring model. ${ }^{4}$

\subsection{Ex-day Returns and Adjustment Factors}

The second prediction of our anchoring model is that if market participants more or less suffer from the anchoring bias, the ex-day returns will be positively associated with the adjustment factors. We test this first-order anchoring effect in this subsection.

Following the approach of Grinblatt et al. (1984), we first divide all distribution events into 20 groups based on the magnitude of the adjustment factors and report the average raw and abnormal returns on ex-days in Table 2. We observe a positive relation between ex-day returns and adjustment factors, although the relation is non-monotonic: the highest abnormal returns are observed for the "large stock dividend" group with adjustment factors between 0.10 and 0.25 . Grinblatt et al. (1984) find a similar pattern without providing plausible explanations. In our anchoring framework, we argue that the moderating effect brought about by the varying degree of investors' anchoring propensity explains the non-monotonic return-factor relation. We perform cross-sectional tests on how the event-varying anchoring propensity influences the ex-day returns in Section 5.

(Insert Table 2 here.)

To visualize the positive return-factor relation, we scatter plot the ex-day returns on the y-axis against the adjustment factors on the $\mathrm{x}$-axis utilizing all of the distribution events. The plot is shown in Figure

${ }^{4}$ Untabulated tests reveal that the average announcement return for stock dividend distributions is $0.65 \%$ and significantly positive, consistent with the signaling hypothesis of Lakonishok and Lev (1987). Consistent with the signaling and optimal trading range hypothesis in Grinblatt et al. (1984), the average announcement return of splits is $1.37 \%$ and significantly positive. The cum-day return is also significantly positive with an average of $0.39 \%$ for stock dividends and $0.19 \%$ for splits. 
IA1 of the Internet Appendix. We further fit a cubic polynomial function and find a positively-sloped fitted curve, which confirms the positive return-factor relation and supports our anchoring hypothesis.

We formally test the hypothesized positive relation between ex-day returns and adjustment factors using the cross-section of all available distribution events as follows:

$$
\text { aret_ex }=a+b \times f+\text { controls, }
$$

where aret_ex is the Carhart four-factor adjusted abnormal return on the ex-day and $f$ is the logarithm of one plus the adjustment factor. The anchoring hypothesis predicts that the coefficient of $f$ is positive. We winsorize variables that are not in the logarithm terms at their respective 1st and 99th percentiles, and the t-statistics are calculated using standard errors clustered by both stock and ex-day.

The control variables include the logarithm of the cum-day price (logprice), with a lower price level indicting higher transaction costs. As splits are usually associated with abnormal pre-event returns (Ikenberry et al. 1996), we control for this momentum using the cumulative return over the prior six months (ret_-6m). Following Grinblatt et al. (1984), we include a Nasdaq indicator that equals one for stocks traded on Nasdaq and zero otherwise, as the market-making mechanism of Nasdaq is associated with higher transaction costs than the centralized auction mechanism of NYSE. We include changes in the share turnover ratio (4Turnover) from cum-day to ex-day (Dennis and Strickland 2003) to further control for microstructure effects. We add a time variable to control for a possible time trend in the ex-day returns, which is defined as the distribution year minus 1926. In some specifications, we explicitly control for the bid-ask spread (spread) on the ex-day, which is defined as the difference between the closing ask and bid scaled by the closing price. ${ }^{5}$ We report the Pearson correlation among these variables in Table 3.

${ }^{5}$ Eades et al. (1984) suggest control of the logarithm of the time lag in calendar days between announcement and distribution, with a shorter lag indicating greater possibility of a continued under-reaction to announcement return. However, 5,813 observations (out of 23,751), including the majority of reverse splits, do not report a specific announcement day. Thus, we do not control for this time 
Consistent with the patterns documented in Table 2 and Figure IA1, the correlation coefficient between aret_ex and factor is 0.16 and significantly positive.

\section{(Insert Table 3 here.)}

Table 4 reports results of the cross-sectional regression of Equation (5). As expected, the coefficient of $f$ is significantly positive at the $1 \%$ level in the univariate regression in Column (1), and remains so in Columns (2) to (7) when we add more control variables. The magnitude of the coefficient of $f$ is rather stable across the columns. These results support the anchoring effect, that is, the ex-day return is positively correlated with the adjustment factor.

(Insert Table 4 here.)

It is worth noting that in Column (7) of Table 4, where we add spread as an additional control, the number of observations is substantially reduced (almost by half) due to data unavailability. The economic magnitude and statistical significance of the coefficient of $f$, however, are not affected. This suggests that controlling for transaction costs does not change the positive return-factor relation predicted by our anchoring hypothesis. The coefficients of other variables are qualitatively unchanged with the control of spread. To preserve a large sample size and for the sake of brevity, we do not explicitly control for spread in the subsequent analyses. Results with the control of spread are available in the Internet Appendix.

\subsection{Subsample Tests}

To examine the robustness of the main results reported in Table 4, we estimate Equation (5) separately for each of the three event types and report the subsample regression results in Table 5. We find robust evidence supporting the anchoring effect: the coefficient of $f$ is significantly positive at the $1 \%$ level for

lag or announcement return. In unreported tests, we also control for the AMEX and Monday dummies, and cum-day return. These control variables do not have significant coefficients and are dropped from the regressions. 
each event type. The anchoring effect appears to be the strongest in the subsample of stock dividend distributions, and the coefficient of $f$ is $8.417(t=5.32)$. In comparison, the coefficient of $f$ is $0.579(t=$ 2.99) for splits and $1.445(t=3.64)$ for reverse splits. We conjecture that the stronger anchoring effect for stock dividends could result from the fact that the investors' anchoring propensity is greater among such events. We discuss the influence of the investors' anchoring propensity in detail in Section 5.

\section{(Insert Table 5 here.)}

When the control variables are examined, it is interesting to note that the influence of several control variables on the ex-day returns is conditional upon the sign of the adjustment factor. Columns (1) and (2) of Table 5 show that for events with positive adjustment factors (stock dividends or splits), stocks with lower prices or listed on Nasdaq are associated with higher ex-day returns. Column (3) shows that for reverse splits, stocks with lower prices or listed on Nasdaq are associated with more negative ex-day returns. Table IA1 of the Internet Appendix further reports that a higher spread is associated with higher returns for stock dividend distributions and splits but lower returns for reverse splits. The evidence is consistent with the microstructure theories discussed in Section 2.3. The coefficient of ret_-6m is significantly positive for every event type, thus indicating that stocks that outperform in the past tend to have higher ex-day returns. Increased turnover leads to higher ex-day returns for splits but lower returns for

reverse splits. Finally, the coefficient of the time trend shows that the ex-day return becomes less positive for stock dividend distributions and splits, and less negative for reverse splits throughout the years, suggesting that the ex-day effect is relatively weaker in the more recent period.

\subsection{Sub-Period Tests}

Reduced transaction costs after decimalization in 2001 (Graham et al. 2003) are expected to be accompanied by intensified arbitrage activities, which could eliminate the pricing errors instigated by investors' cognitive biases including anchoring. Hence, we perform tests based on Equation (5) in sub-periods before and after decimalization to examine whether the anchoring effect still exists in the post-decimalization era. We categorize events on and before 2001 as the pre-decimalization period, and 
set a dummy variable Pre2002 that equals to one for the pre-decimalization period and zero for the postdecimalization period.

Table 6 reports results of the sub-period tests. We first conduct the test for the full sample with all three types of events and report the results in Panel A. When we regress the ex-day return on $f$ in the multivariate regression, the coefficient of $f$ is 2.961 ( $t=18.85$, Column 1$)$ before decimalization and drops to 0.829 ( $t=2.67$, Column 2$)$ after decimalization. The coefficient of the interaction term $f \times$ Pre2002 is significantly positive with a magnitude of $1.188(t=6.58$, Column 3$)$. The results suggest that the anchoring effect is declining but remains after decimalization. We further perform the sub-period tests by event type and report the results in Panel B. The coefficient of $f$ remains significantly positive in every sub-period and for each event type, supporting our anchoring hypothesis. Moreover, controlling for spread in the regressions (Table IA2 in the Internet Appendix) does not qualitatively change the results.

\section{(Insert Table 6 here.)}

In sum, we find strong evidence that the ex-day abnormal return is positively associated with the adjustment factor. We find this positive return-factor relation in every type of distribution event, and in both periods before and after decimalization. The evidence is consistent with our anchoring argument and cannot be reconciled with the existing microstructure explanations.

\section{Moderating Effect of Anchoring Propensity}

As discussed in Section 3, investors tend to anchor on the cum-day price in valuating stocks on the ex-day, and their adjustment for the stock distribution events is usually insufficient, resulting in a positive return-factor relation documented in Section 4. In this section, we examine how investors' anchoring propensity, which varies across events, influences the ex-day return through the moderating effect as predicted in our anchoring model. 


\subsection{Measures of Anchoring Propensity}

We follow prior literature to develop several measures to capture the event-varying anchoring propensity. First, the anchoring propensity is reduced if investors pay more attention to the adjustment process (Epley and Gilovich 2005). Attention-grabbing distributions draw investors' attention to the events as well as the related adjustment process, which reduces the weight attached to the anchor and results in a lower anchoring propensity. We argue that salient stock distribution events are likely to draw more investor attention. For instance, a 2-for-1 split, which is associated with a large ex-day price movement, is arguably more prominent and attracts more attention than a 5\% stock dividend. We define a dummy variable, salience, that equals one for salient events, including 3-for-2, 2-for-1, 3-for-1, or 4-for-1 splits, or 1-for-2, 1-for-3, 1-for-4, 1-for-5, 1-for-10, or 1-for-20 reverse splits, and zero for other events. ${ }^{6}$ We expect salient events to be associated with a lower anchoring propensity.

Besides, Hirshleifer et al. (2009) suggest that more extraneous news events, with earnings announcements of other firms as the most attention-grabbing ones, distract investors' attention and lead to under-reaction to events. Accordingly, we count the number of earnings announcements made by other firms on the ex-day. We then sort events into ten groups based on the counted number, and denote the ranking as \#news. On days with more extraneous news (\#news) in the markets, investors are more likely to be distracted, pay less attention to the distribution events, and show a greater anchoring propensity.

We develop the second group of anchoring propensity measures from the perspective of arbitrage difficulty. The extent to which psychological biases could affect asset prices depends on whether limits to arbitrage prevent arbitrageurs from fully eliminating the mispricing. Therefore, stocks with greater arbitrage difficulties are expected to be more affected by investors' anchoring propensity. We capture

${ }^{6}$ The results are robust to alternative definition of salient events. For example, the findings remain qualitatively unchanged if 5-for-4 splits (25\% stock dividends) are categorized as salient events, or if 3-for-2 splits are defined as non-salient events. 
arbitrage difficulties using transaction costs and idiosyncratic volatility, following past studies (Pontiff 2006, Shleifer and Vishny 1997, Wurgler and Zhuravskaya 2002). We use spread to measure the direct execution cost of arbitrage activities, calculated as the difference between the closing ask and bid, scaled by the closing price on the ex-day. We follow Kumar (2009a) to compute idiosyncratic volatility (idiovol) for each event as the variance of residuals obtained by regressing daily excess stock returns on Carhart four factors over the prior six months. We expect events with higher spread and/or higher idiovol to be associated with a greater anchoring propensity.

We construct the third group of anchoring propensity measures from the perspective of valuation uncertainty. Anchoring, as a heuristic, helps people to accomplish the estimation task in a cost-effective way. The anchoring heuristic is more likely to be elicited in the case of greater valuation uncertainty (Tversky and Kahneman 1974). Higher idiovol, in addition to indicating greater arbitrage difficulty, is also associated with greater valuation uncertainty (Kumar 2009a). In addition, young firms with limited past records are difficult to value (Kumar 2009a). We therefore measure firm age (age) as the number of years between the year of the event and the first appearance of the firm in the CRSP database, and expect investors’ anchoring propensity to be negatively associated with age.

The fourth group of anchoring propensity measures focus on the average level of shareholder sophistication. Institutional investors are arguably more sophisticated and therefore suffer from less anchoring bias. Thus, stocks with higher institutional ownership (IO) should be less affected by the anchoring bias. ${ }^{7} \mathrm{IO}$ refers to aggregate institutional ownership at the stock-level in quarterly $13 \mathrm{~F}$ filings

7 Jones and Lamont (2002) also use a lower IO to proxy for more binding short-sale constraints, as shares owned by financial institutions are the potential supply of security-lending used for short sales. By this logic, a lower $I O$ also indicates a greater anchoring propensity due to greater arbitrage difficulty. 
immediately before the event. ${ }^{8}$ Furthermore, Kumar (2009b), among others, show that low-priced stocks are favored by unsophisticated individual investors but avoided by institutional investors. We thus expect investors’ anchoring propensity to be greater among stocks with a lower cum-day price (price).

Lastly, we use market-wide sentiment to capture the time variation in investors' anchoring propensity. Stambaugh et al. (2012) document stronger asset pricing anomalies following high market sentiment. Yu and Yuan (2011) find that high market sentiment is accompanied by the active participation of noise traders, who are heavily affected by various cognitive biases including anchoring. We employ the monthly market sentiment index of Baker and Wurgler (2006) and expect events that take place following higher sentiment (denoted as sentiment) to be more affected by investors’ anchoring propensity. ${ }^{9}$

In total, we use these eight measures to capture investors' anchoring propensity from five different perspectives. ${ }^{10}$ Table IA3 in the Internet Appendix reports the average of these eight anchoring propensity measures for each event type and the correlation among these measures.

${ }^{8}$ We set $I O$ to 0 for firms without records in $13 \mathrm{~F}$ filings and to missing for firms with a calculated $I O$ that is more than $100 \%$.

${ }^{9}$ We obtain the monthly market sentiment data from http://people.stern.nyu.edu/jwurgler/.

10 In addition to the eight aforementioned anchoring propensity measures, our results remain qualitatively similar when adopting alternative anchoring propensity measures. With regard to valuation uncertainty, we use total volatility (totvol) calculated as the variance of daily returns in the six-month period prior to distribution, market volatility (mktvol) measured as the difference between totvol and idiovol, and price volatility (prcvol) measured as the variance of daily unadjusted price one-month prior to the distribution event and scaled by the unadjusted cum-day price. Baker and Wurgler (2006) argue that unprofitable firms have greater valuation uncertainty as the traditional discounted cash flow pricing method could not be applied. We set a dummy variable negE that equals one for firms with negative income before extraordinary items over the previous quarter and zero otherwise. Firms with negative 


\subsection{Moderating Effect of Anchoring Propensity}

We first examine whether ex-day returns vary with the set of anchoring propensity measures, holding the adjustment factor constant. For events with the same adjustment factor, our anchoring model predicts that a greater anchoring propensity magnifies the anchoring-induced ex-day returns. Specifically, we examine events with an adjustment factor that equals to $0.05,1$, or -0.9 . We choose these three factors as they have the largest number of observations in each event type. We regress ex-day abnormal returns on each of the seven anchoring propensity measures (salience is not included as it is constant for a fixed adjustment factor). We control for prior six-month returns, changes in turnover ratio, the Nasdaq indicator, and the time trend. The cross-sectional regression results are reported in Table IA4 in the Internet Appendix. As expected, a greater anchoring propensity is associated with higher ex-day returns for stock dividend distributions and splits. For reverse splits, however, a greater anchoring propensity is associated with more negative ex-day returns. The evidence is consistent with our anchoring hypothesis that the event-varying anchoring propensity drives within-factor variation in ex-day returns as shown in Figure IA1 in the Internet Appendix.

Next, we examine the moderating effect of anchoring propensity on the return-factor relation. We first show a graphical representation using scatter plots. We divide the full sample into two groups based on each of the eight anchoring propensity measures. Figure 1(a), with ex-day returns on the y-axis and the adjustment factors on the x-axis, shows that the return-factor relation is positive for both non-salient (left figure) and salient (right figure) events. However, the slope for non-salient events is much steeper than

earnings are expected to have a greater anchoring propensity. With regard to stock characteristic preferred by unsophisticated individual investors, we include the idiosyncratic skewness of stock returns (skew) measured as the skewness of the residuals obtained by regressing daily excess stock returns on Carhart four factors over a six-month period prior to the distribution event. For brevity, we report the results of these tests in Table IA5 of the Internet Appendix. 
that for salient events, indicating that attenuated attention to the events enhances the anchoring effect. The seven remaining panels of Figure 1 consistently show that the positive return-factor relation is more prevalent for groups with a greater anchoring propensity, including those with more \#news, higher spread, higher idiovol, lower age, lower $I O$, lower price, and higher sentiment.

(Insert Figure 1 here.)

Next, we formally test the moderating effects using cross-sectional multivariate regression

$$
\text { aret_ex }=a+b_{1} \times f+b_{2} \times \gamma \times f+\text { controls, }
$$

where $\gamma$ represents alternative measures of investors' anchoring propensity. The variable of interest is $\gamma \times f$, which captures the moderating effect instigated by the investors' anchoring propensity. When a higher $\gamma$ indicates a greater (lower) anchoring propensity, the coefficient of the interaction term $\gamma \times f$, is expected to be positive (negative). Control variables include the logarithm of the cum-day stock price, pre-event cumulative returns, changes in turnover, Nasdaq dummy, and time trend as shown in Equation (5).

We report the results in Table 7. In Column (1) where the anchoring propensity is measured by salience, the coefficient of $f$ is 2.967 ( $t=11.74)$, indicating a significant anchoring effect for non-salient events. The coefficient of the interaction term salience $\times f$ is -0.849 and significantly negative ( $t=3.38)$, indicating that the anchoring effect is statsitically weaker for salient events with more investors' attention. In Column (2) where the anchoring propensity is measured by \#news, the coefficient of the interaction term \#news $\times f$ is significantly positive, which is consistent with our expectation that the anchoring effect is reinforced on days with more distracting news. In Columns (3) and (4), the coefficients of the interaction terms spread $\times f$ and idiovol $\times f$ are both significantly positive, consistent with our expectation that the anchoring effect is stronger when the arbitrage difficulty is greater. In Column (5) where firm age is used to proxy for valuation uncertainty, the coefficient of logage $\times f$ is significantly negative. This suggests that the anchoring effect is stronger for younger firms that arguably have greater valuation uncertainty. About the influence of investor sophistication, Column (6) reports a significantly negative coefficient of $I O \times f$, suggesting that stocks with higher institutional holding exhibit a weaker anchoring effect. The significantly 
negative coefficient on logprice $\times f$ in Column (7) confirms that the anchoring effect is stronger among low-priced stocks that are favored by unsophisticated individual investors. Finally, events that follow higher market sentiment exhibit a stronger anchoring effect, as suggested by the significantly positive coefficient of sentiment $\times f$ in Column (8). ${ }^{11}$

(Insert Table 7 here.)

\subsection{Further Evidence Based on Brokerage Account-Level Data}

We proceed one step further and explore the brokerage account data used in Barber and Odean (2000) to provide direct evidence based on the characteristics of the individual investors who trade the event stocks. This dataset contains end-of-month portfolio positions of individual investors of a major U.S. discount brokerage house from 1991 to 1996 . There are 77,995 investors in the database and 62,387 have traded common stocks. This dataset has been widely used in prior studies on individual trading and preference (e.g., Barber and Odean (2000), Kumar (2009b)). We assume that these individual investors of the large brokerage house are representative of the aggregated individual investor clientele.

We construct four anchoring propensity measures based on the brokerage data. First, for each stock undergoing the distribution event, we calculate its weight in the portfolio of the individual investors of the brokerage house in excess of its weight in the market portfolio. A greater excess weight indicates that the

11 The empirical evidence on the moderating effect of anchoring propensity is robust to controlling for the bid-ask spread on the ex-day, and the results are reported in Table IA6 in the Internet Appendix. The results are qualitatively unchanged even though the sample size is substantially reduced due to data availability. We also examine the moderating effect of anchoring propensity within the subsample of stock dividend distributions and report the results in Table IA7 in the Internet Appendix. The evidence is relatively weaker for this subsample test, which could be due to the much smaller sample size. 
stock receives disproportionately more investment from individual investors and thus could be more affected by investors' anchoring bias. Variable ExcessWt equals one if the excess weight is above the median and zero otherwise. The second measure, Equity, is the average equity position of investors holding the event stock. Investors with more exposure to the stock market are expected to be more sophisticated or more experienced in investment. Thus, a higher Equity indicates a lower anchoring propensity. The third and fourth measures, InvExp1 and InvExp2, focus on the past investment experience of investors. For each investor trading the event stock, we calculate her investment experience in the number of years since she opened her account with the brokerage house. We then take the stock-level average and label it as InvExp1. For each investor trading the event stock, we also count her number of trades prior to the event. We then take the stock-level average and label it as InvExp2. Both InvExp1 and InvExp2 have been widely used in the literature to quantify investors' investment experience, or the learning effect (e.g., Dhar and Zhu (2006), Kumar (2009b), Kuo et al. (2015), Seru et al. (2010)). We expect stocks with more experienced investors to have a lower anchoring propensity.

We estimate Equation (6) using the four measures from the brokerage data to capture $\gamma$ and report the results in Table 8. First, the significantly positive coefficient of ExcessWt $\times f$ in Column (2) suggests that stocks that are disproportionately invested more by individual investors, who are expected to be less sophisticated and have a greater anchoring propensity, tend to have a stronger return-factor relation. In Column (3) where the anchoring propensity is captured by the average size of investors' equity portfolio, the coefficient of Equity $\times f$ is significantly negative, suggesting that the positive return-factor relation is attenuated when the average equity position of investors holding the stock is large. In Columns (4) and (5), where the two investment experience measures are used, the coefficients of the interaction terms are significantly negative in both columns. This suggests that the anchoring effect is weaker if average investors trading the event stock have more past investment experience. This is also consistent with findings from the literature that investors learn from their past investments and therefore are less affected by the anchoring bias, resulting in a weaker return-factor relation. 
(Insert Table 8 here.)

\section{Further Discussion}

\subsection{Post-Event Returns}

If the ex-day return is at least partially driven by investors' anchoring bias, it is likely to be transient and reversed in the post-event period. For each type of distribution event, Figure IA2 of the Internet Appendix plots the average abnormal return $(A R)$ and cumulative abnormal return $(C A R)$ over 20 trading days before and 60 trading days after the event. Panels (a) and (b) show that both stock dividend distributions and splits experience positive pre-event returns and a prominent post-event reversal. In sharp contrast, the negative returns persist for reverse splits, as shown by Panel (c). The observation is consistent with the results in Panel E of Table 1, which reports statistics of CARs in 20 trading days after the ex-day. The average post-event return is $-0.86 \%$ for stock dividend distributions, $0.25 \%$ for splits, and $-3.91 \%$ for reverse splits. We use the following cross-sectional regression to investigate the post-event return patterns

$$
\text { car_post }=a+b \times \text { aret_ex }+ \text { controls, }
$$

where car_post is the cumulative abnormal return in 20 trading days after the event, and aret_ex is the ex-day abnormal return in Equations (5) and (6). If part of the ex-day return is transient and reversed, we expect a negative coefficient of aret_ex. Control variables include the logarithm of the cum-day price, before-event cumulative returns, change in (average) turnover ratio from ex-day to the post-event period ( $\Delta$ turnover), the Nasdaq indicator, and the time trend.

Table 9 reports the regression results. Column (1) shows that for the full sample, the coefficient of aret_ex is $-0.181(t=8.13)$, which is significantly negative at the $1 \%$ level, thus confirming the cross-sectional return reversal pattern. Columns (2) to (4) further show that this reversal pattern exists in each of the three event types. The coefficient of aret_ex is $-0.290(t=7.39)$ for stock dividend distributions in Column (2), $-0.276(t=8.48)$ for splits in Column (3), and $-0.150(t=3.92)$ for reverse splits in Column (4). The evidence suggests that there is a transient proportion in ex-day returns, which is reversed in the 
post-event period. This is consistent with our argument that the ex-day return is partially driven by investors’ anchoring bias.

\section{(Insert Table 9 here.)}

We further control for post-event profitability, measured by the post-event quarterly return on equity (ROE), and report the results in Panel A of Table IA8 in the Internet Appendix. The variable ROE is positively associated with post-event returns. Furthermore, after controlling for ROE, we still observe a significantly negative coefficient of aret_ex for both the full sample and each event type. We then add spread in the regression in Panel B of Table IA8, and the reversal pattern remains. While we extend the post-event period from 20 trading days to 60 trading days in Panel C, there is still a significant reversal pattern for stock dividend distributions and splits, but not for reverse splits.

One might wonder why the reverse splits exhibit a return reversal pattern in the cross-sectional test in Table 9 but a return continuation pattern at the aggregate level in Figure IA2. We argue that the post-event performance could reconcile this difference. Unreported summary statistics show that the average ROE of these firms is as low as $-10.46 \%$ before the events, average book-to-market ratio is 1.44 , and average cum-day price is only $\$ 2.12$ (with an extremely low median of $\$ 0.62$ ). This is not surprising as poor performance is often accompanied with low stock price, and managers of such firms have strong incentives to conduct reserve splits to bring the stock price back to desired price range (Han 1995). For these firms, the average aret_ex is $-4.55 \%$ (Panel A of Table 1). When the post-event return is regressed on aret_ex, the coefficient of aret_ex is -0.182 , which is significantly negative (Column 4 of Panel A, Table IA8). This means that a post-event return of $0.83 \%$ is due to the cross-sectional reversal of the ex-day returns. However, unreported test shows that the average post-event $R O E$ is $-10.39 \%$, and the coefficient on ROE (\%) is 0.070 (Column 4 of Panel A, Table IA8), translating into an average post-event return of $-0.73 \%$ (Column 4 of Panel A, Table IA8). Thus, the negative post-event return due to poor performance $(-0.73 \%)$ offsets the majority of the positive post-event returns due to the reversal of the ex-day return $(0.83 \%)$. After the negative intercept $(-4.32 \%)$ is taken into account, it explains why we observe a 
continuation of the post-event return at the aggregate level, but witness a reversal in the cross-section of events for the reverse-split firms.

\subsection{Microstructure Explanations}

As summarized in Section 2.3, microstructure theories are mainly used in prior studies to explain ex-day returns. We have added the bid-ask spread in the regressions to control for this microstructure effect. In this section, we take a closer look at the changes in liquidity around the distribution events. We employ three liquidity measures: daily turnover ratio, bid-ask spread, and the location parameter. In particular, turnover is the daily trading volume in shares scaled by outstanding shares, spread is daily (askbid)/close price, and location parameter (Conrad and Conroy 1994) is daily (close price-bid)/(ask-bid). The location parameter ranges between zero and one, with a higher ratio indicating a higher likelihood for the price to close at the ask and, therefore, greater buy-order imbalance.

We align the observation window by event time in trading days and aggregate the liquidity measures for each type of distribution event. Figure IA3 in the Internet Appendix shows the time-series variation in liquidity around distribution events, and Table IA9 in the Internet Appendix reports the paired $t$-test of liquidity measures from cum-day to ex-day. For stock dividend distributions, we find deteriorating liquidity on the ex-day as shown by a lower turnover and higher spread. We do not find a higher location parameter on the ex-day. Thus, the bid-ask bounce hypothesis cannot explain the ex-day returns for stock dividend distributions. For splits, we find higher spread and higher location parameter on the ex-day, supporting the optimal trading range hypothesis. For reverse splits, we find both increased turnover and higher spread on the ex-day.

As a further robustness check, we control for location parameter in Equation (5) and report the results in Column (1) of Table 10. The positive return-factor relation remains, which suggests that our anchoring argument is robust to the control of the bid-ask bounce. Then, we use the bid-to-bid abnormal return on the ex-day, which is not contaminated by the bid-ask bounce, as the dependent variable and re-estimate Equation (5). The positive return-factor relation persists as shown in Column (2). 
(Insert Table 10 here.)

Next, we examine whether price discreteness (Bali and Hite 1998) subsumes the explanatory power of anchoring bias for ex-day returns. We follow Graham et al. (2003) to assign tick size to NYSE stocks. In particular, the tick size is 1/8 before 23 June 1997, 1/16 from 24 June 1997 to 26 August 2000, and 0.01 after 29 January 2001. We calculate the rational ex-day price using Equation (1) and then round the rational ex-day price up to the nearest tick. We then scale the dollar rounding error by the rational price to obtain the rounding return. We add rounding return as an additional control variable in Equation (5) and report the regression results in Column (3) of Table 10. Only the subsample of NYSE stocks is used and the number of available observations is approximately half of the original sample. Consistent with the price discreteness explanation, we find that rounding return is significantly positively associated with the ex-day return. Nevertheless, after controlling for price discreteness, we still find a positive return-factor relation. Therefore, price discreteness cannot subsume the anchoring effect.

Following Dennis and Strickland (2003), we also examine changes in IO around stock distributions. Pre-event $I O$ is based on the last $13 \mathrm{~F}$ filing before distribution and the post-event $I O$ is based on the first 13F filing after distribution. Panel D of Table IA9 in the Internet Appendix shows that IO changes insignificantly from $5.61 \%$ to $5.65 \%$ for stock dividend distributions. IO increases slightly from $19.97 \%$ to $20.37 \%$ after splits. For reverse splits, $I O$ increases significantly from $1.35 \%$ to $7.49 \%$, supporting the optimal trading range hypothesis. Column (6) of Table 7 has shown that controlling for the pre-event $I O$ in Equation (5) does not change the positive correlation between the ex-day return and the adjustment factor. Unreported results further indicate that changing the pre-event $I O$ to post-event $I O$ or changes in IO does not alter the positive return-factor relation. Thus, the anchoring effect is robust to the control of ownership structure.

\subsection{When-Issued Trading}

Nayar and Rozeff (2001) use when-issued shares to test the inconvenience hypothesis of stock splits. The when-issued hypothesis, however, does not apply to stock dividend distributions, which typically do not 
have a when-issued market. Thus, the positive ex-day abnormal returns for stock dividend distributions cannot be attributed to the order transfers between the when-issued and regular markets. Second, for stock distributions events (including stock dividends), even if investors find inconvenience in trading odd lots, the inconvenience-caused price discounts should only exist near the record date but disappear afterwards, as stocks purchased after the record date are no longer entitled to receive the odd lots. Thus, trading inconvenience might explain abnormal returns after the record days, but not on the ex-days. Third, the odd lots should be less relevant in a world of electronic trading (Weld et al. 2009). However, we still observe non-trivial ex-day returns for stock distribution events in the post-decimalization period and even slightly higher ex-day returns for stock dividends (Panel C of Table 1). Thus, the inconvenience hypothesis is not likely to be the major driving force of ex-day returns, especially for stock dividends.

\section{Conclusion}

In this study, we propose a new explanation for the puzzling ex-day returns. We model and test whether investors' anchoring bias contributes to the abnormal returns on the ex-distribution day. As investors tend to reply on the cum-day price as a naive anchor in determining the ex-day price, we predict the ex-day return to increase with the adjustment factor. We find a strong and robust positive relation between the ex-day abnormal return and the adjustment factor for each event type and in the periods both before and after decimalization. Moreover, the positive return-factor relation is more prominent among events where the investors' anchoring propensity is expected to be greater. Finally, we document that part of the ex-day abnormal return is transient and reversed during the post-event period, which is consistent with our conjecture that the ex-day return is at least partially driven by investors' anchoring bias. Overall, our study offers new evidence for the ex-day anomaly and adds to the literature on the impact of anchoring bias on asset pricing. 


\section{References}

Baker M, Pan X, Wurgler J (2012). The effect of reference point prices on mergers and acquisitions. Journal of Financial Economics. 106(1): 49-71.

Baker M, Wurgler J (2006). Investor sentiment and the cross-section of stock returns. The Journal of Finance. 61(4): 1645-1680.

Bali R, Hite GL (1998). Ex dividend day stock price behavior: Discreteness or tax-induced clienteles? Journal of Financial Economics. 47(2): 127-159.

Barber BM, Odean T (2000). Trading is hazardous to your wealth: The common stock investment performance of individual investors. The Journal of Finance. 55(2): 773-806.

Beggs A, Graddy K (2009). Anchoring effects: Evidence from art auctions. American Economic Review. 99(3): 1027-1039.

Campbell SD, Sharpe SA (2009). Anchoring bias in consensus forecasts and its effect on market prices. Journal of Financial and Quantitative Analysis. 44(02): 369-390.

Carhart MM (1997). On persistence in mutual fund performance. The Journal of Finance. 52(1): 57-82.

Cen L, Hilary G, Wei KCJ (2013). The role of anchoring bias in the equity market: Evidence from analysts' earnings forecasts and stock returns. Journal of Financial and Quantitative Analysis. 48(01): 47-76.

Chang EC, Luo Y, Ren J (2013). Cross-listing and pricing efficiency: The informational and anchoring role played by the reference price. Journal of Banking \& Finance. 37(11): 4449-4464.

Chung KH, Chuwonganant C, McCormick DT (2004). Order preferencing and market quality on NASDAQ before and after decimalization. Journal of Financial Economics. 71(3): 581-612.

Conrad JS, Conroy R (1994). Market microstructure and the ex-date return. The Journal of Finance. 49(4): 1507-1519.

Dennis P, Strickland D (2003). The effect of stock splits on liquidity and excess returns: Evidence from shareholder ownership composition. Journal of Financial Research. 26(3): 355-370.

Dhar R, Zhu N (2006). Up close and personal: Investor sophistication and the disposition effect. Management Science. 52(5): 726-740.

Dougal C, Engelberg J, Parsons CA, Van Wesep ED (2015). Anchoring on credit spreads. The Journal of Finance. 70(3): 1039-1080.

Eades KM, Hess PJ, Kim EH (1984). On interpreting security returns during the ex-dividend period. Journal of Financial Economics. 13(1): 3-34.

Easley D, O’Hara M, Saar G (2001). How stock splits affect trading: A microstructure approach. Journal of Financial and Quantitative Analysis. 36(01): 25-51.

Elton EJ, Gruber MJ (1970). Marginal stockholder tax rates and the clientele effect. The Review of Economics and Statistics. 52(1): 68-74. 
Epley N, Gilovich T (2005). When effortful thinking influences judgmental anchoring: Differential effects of forewarning and incentives on self-generated and externally provided anchors. Journal of Behavioral Decision Making. 18(3): 199-212.

Frank M, Jagannathan R (1998). Why do stock prices drop by less than the value of the dividend? Evidence from a country without taxes. Journal of Financial Economics. 47(2): 161-188.

Galinsky AD, Mussweiler T (2001). First offers as anchors: The role of perspective-taking and negotiator focus. Journal of Personality and Social Psychology. 81(4): 657-669.

Genesove D, Mayer C (2001). Loss aversion and seller behavior: Evidence from the housing market. The Quarterly Journal of Economics. 116(4): 1233-1260.

George TJ, Hwang C-Y (2004). The 52-week high and momentum investing. The Journal of Finance. 59(5): 2145-2176.

Graham JR, Michaely R, Roberts MR (2003). Do price discreteness and transactions costs affect stock returns? Comparing ex-dividend pricing before and after decimalization. The Journal of Finance. 58(6): 2611-2635.

Grinblatt MS, Masulis RW, Titman S (1984). The valuation effects of stock splits and stock dividends. Journal of Financial Economics. 13(4): 461-490.

Han KC (1995). The effects of reverse splits on the liquidity of the stock. The Journal of Financial and Quantitative Analysis. 30(1): 159-169.

Hirshleifer D (2001). Investor psychology and asset pricing. The Journal of Finance. 56(4): 1533-1597.

Hirshleifer D, Lim SS, Teoh SH (2009). Driven to distraction: Extraneous events and underreaction to earnings news. The Journal of Finance. 64(5): 2289-2325.

Ikenberry DL, Rankine G, Stice EK (1996). What do stock splits really signal? Journal of Financial and Quantitative analysis. 31(03): 357-375.

Jones CM, Lamont OA (2002). Short-sale constraints and stock returns. Journal of Financial Economics. 66(2-3): 207-239.

Karpoff JM, Walkling RA (1990). Dividend capture in NASDAQ stocks. Journal of Financial Economics. 28(1-2): 39-65.

Kumar A (2009a). Hard-to-value stocks, behavioral biases, and informed trading. The Journal of Financial and Quantitative Analysis. 44(6): 1375-1401.

Kumar A (2009b). Who gambles in the stock market? The Journal of Finance. 64(4): 1889-1933.

Kuo W-Y, Lin T-C, Zhao J (2015). Cognitive limitation and investment performance: Evidence from limit order clustering. Review of Financial Studies. 28(3): 838-875.

Lakonishok J, Lev B (1987). Stock splits and stock dividends: Why, who, and when. The Journal of Finance. 42(4): 913-932. 
Lambson VE, McQueen GR, Slade BA (2004). Do out-of-state buyers pay more for real estate? An examination of anchoring - induced bias and search costs. Real Estate Economics. 32(1): 85-126.

Lamoureux CG, Poon P (1987). The market reaction to stock splits. The Journal of Finance. 42(5): 1347-1370.

Lopes LL (1985). Averaging rules and adjustment processes in bayesian inference. Bulletin of the Psychonomic Society. 23(6): 509-512.

Maloney MT, Mulherin JH (1992). The effects of splitting on the ex: A microstructure reconciliation. Financial Management. 21(4): 44-59.

Nayar N, Rozeff MS (2001). Record date, when-issued, and ex-date effects in stock splits. The Journal of Financial and Quantitative Analysis. 36(1): 119-139.

Northcraft GB, Neale MA (1987). Experts, amateurs, and real estate: An anchoring-and-adjustment perspective on property pricing decisions. Organizational Behavior and Human Decision Processes. 39(1): 84-97.

Pontiff J (2006). Costly arbitrage and the myth of idiosyncratic risk. Journal of Accounting and Economics. 42(1-2): 35-52.

Seru A, Shumway T, Stoffman N (2010). Learning by trading. Review of Financial studies. 23(2): 705-739.

Shafir E, Diamond P, Tversky A (1997). Money illusion. The Quarterly Journal of Economics. 112(2): 341-374.

Shleifer A, Vishny RW (1997). The limits of arbitrage. The Journal of Finance. 52(1): 35-55.

Stambaugh RF, Yu J, Yuan Y (2012). The short of it: Investor sentiment and anomalies. Journal of Financial Economics. 104(2): 288-302.

Tversky A, Kahneman D (1974). Judgment under uncertainty: Heuristics and biases. Science. 185(4157): $1124-1131$.

Weld WC, Michaely R, Thaler RH, Benartzi S (2009). The nominal share price puzzle. The Journal of Economic Perspectives. 23(2): 121-142.

Woolridge JR, Chambers DR (1983). Reverse splits and shareholder wealth. Financial Management. 12(3): 5-15.

Wurgler J, Zhuravskaya E (2002). Does arbitrage flatten demand curves for stocks? The Journal of Business. 75(4): 583-608.

Yu J, Yuan Y (2011). Investor sentiment and the mean-variance relation. Journal of Financial Economics. 100(2): 367-381. 


\section{Figures and Tables}

\section{Figure 1: Influence of Anchoring Propensity}

For each of the anchoring propensity measure, we divide the full sample into two subsamples based on its sample median. Measures of anchoring propensity include the salience of events (salience), number of concurring earnings announcements on the ex-day (\#news), idiosyncratic volatility (IV), bid-ask spread on the ex-day (spread), institutional ownership (IO), cum-day price (price), firm age (age), and market sentiment in the previous month (sentiment). The only exception is in Panel (a), where two groups are formed based on whether salience is 0 or 1 . We winsorize returns at the top and bottom one percentiles. For each subsample, we scatter plot the ex-day abnormal returns in percentage (aret_ex) on the y-axis and adjustment factors on the $\mathrm{x}$-axis with asterisks. We fit a linear function, which is shown by the thick red line. For each anchoring propensity measure, the left figure is for the subsample with a lower value of the measure, and the right figure is for the subsample with a higher value of the measure.

(a): Salience
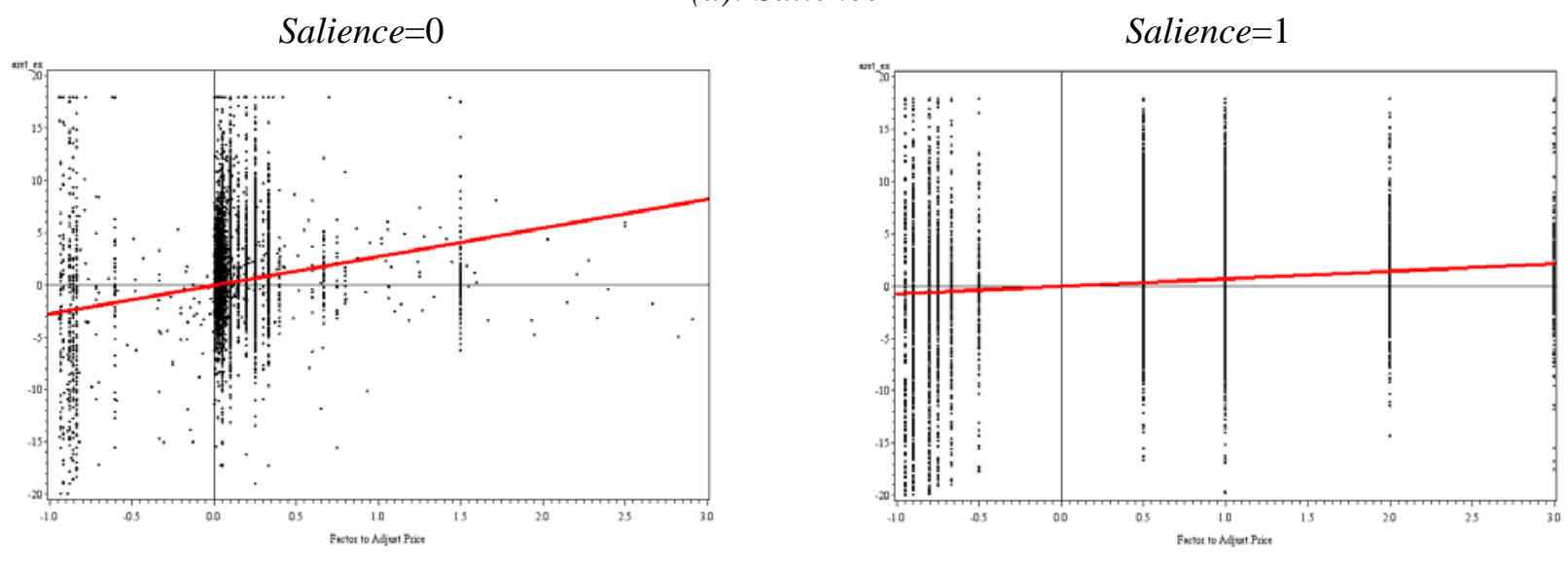

(b): \#news

Low \#news

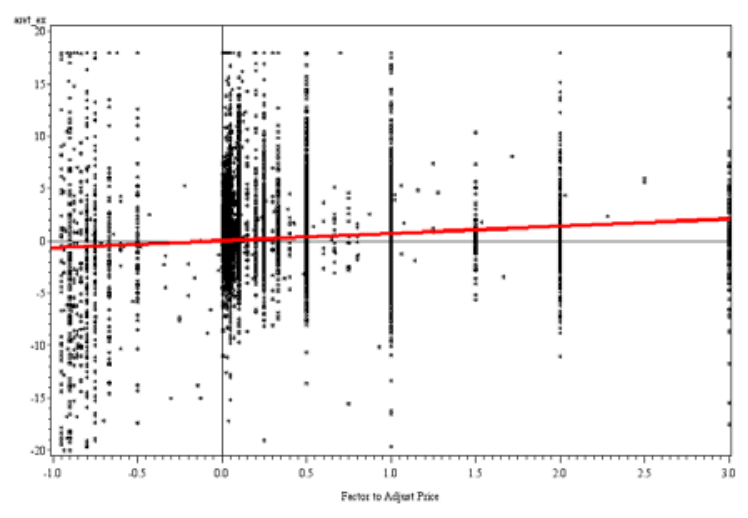

High \#news

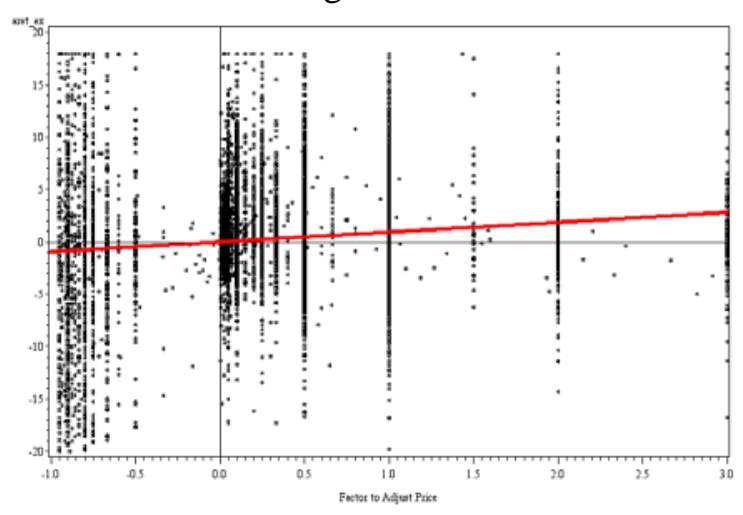


(c): Ex-day bid-ask spread (spread)
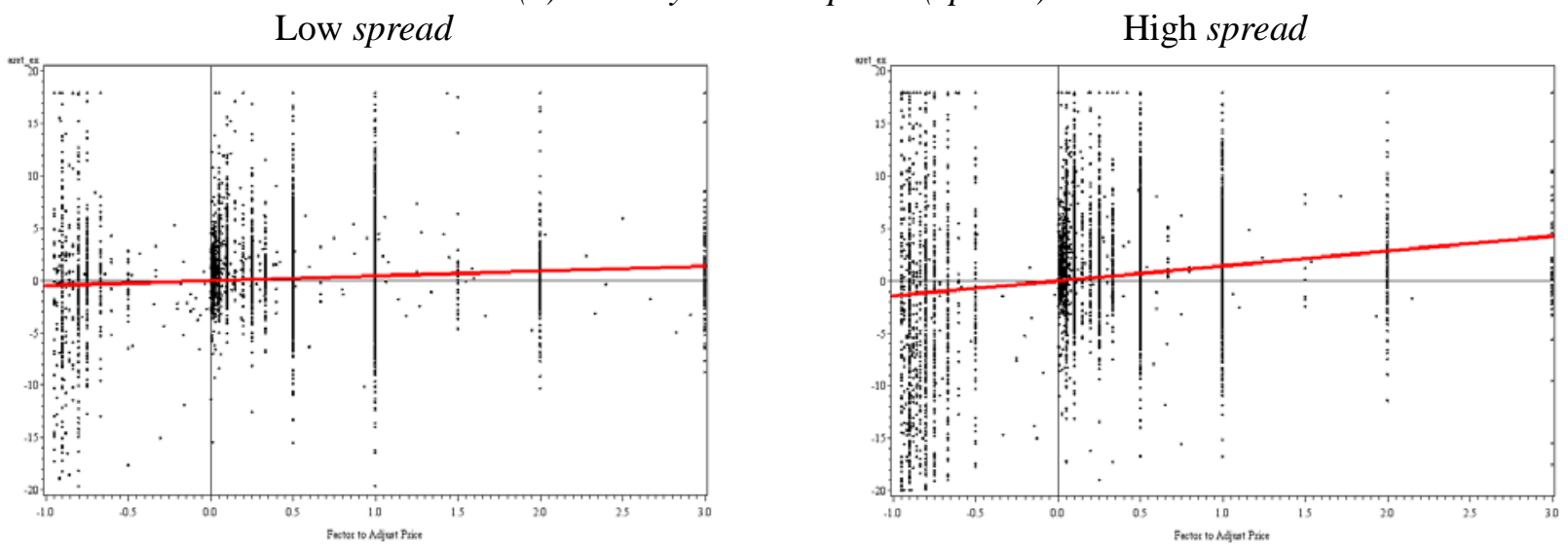

Low idiovol

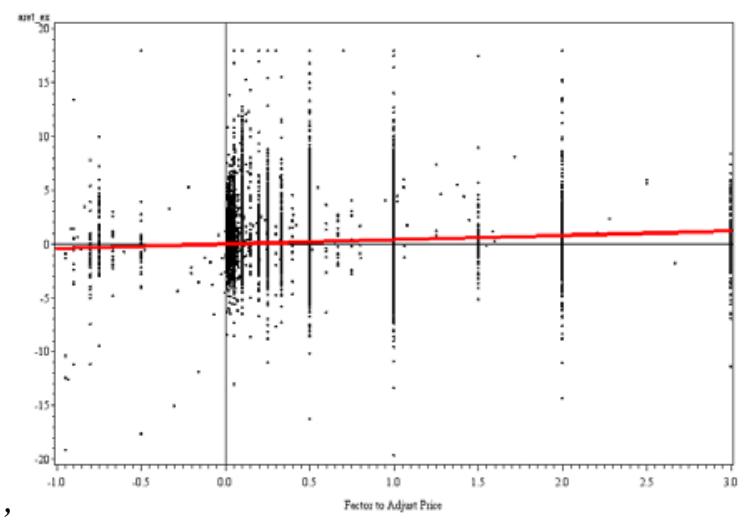

High idiovol

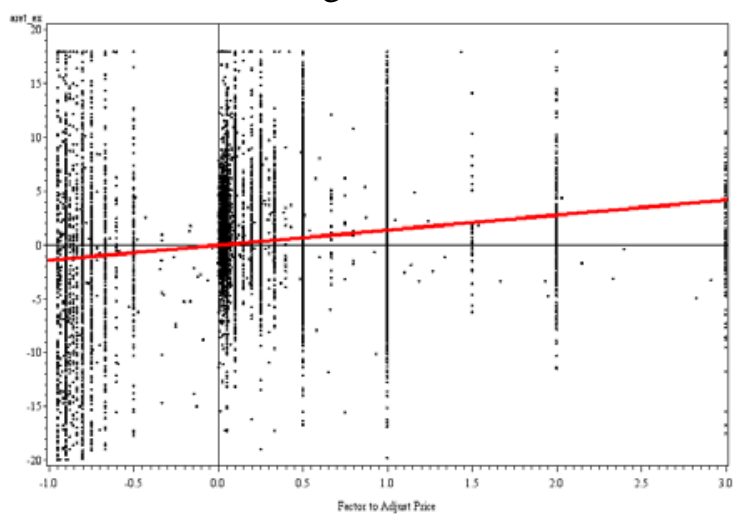

(e): Firm age

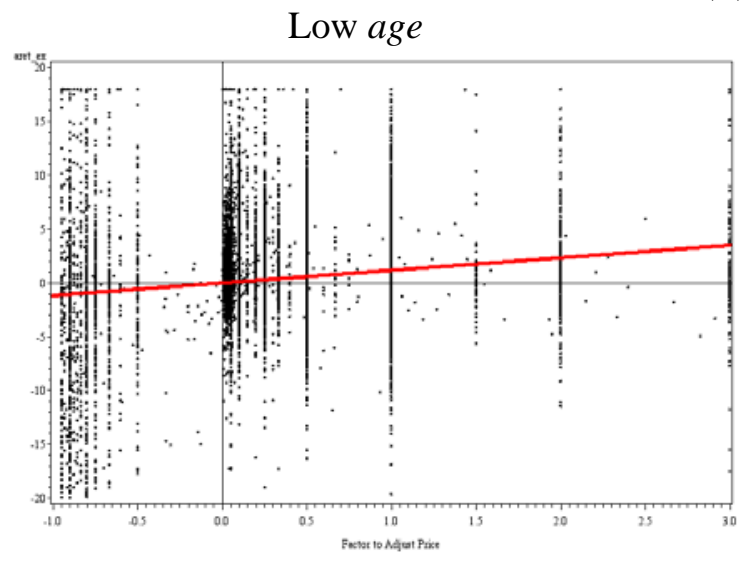

High age

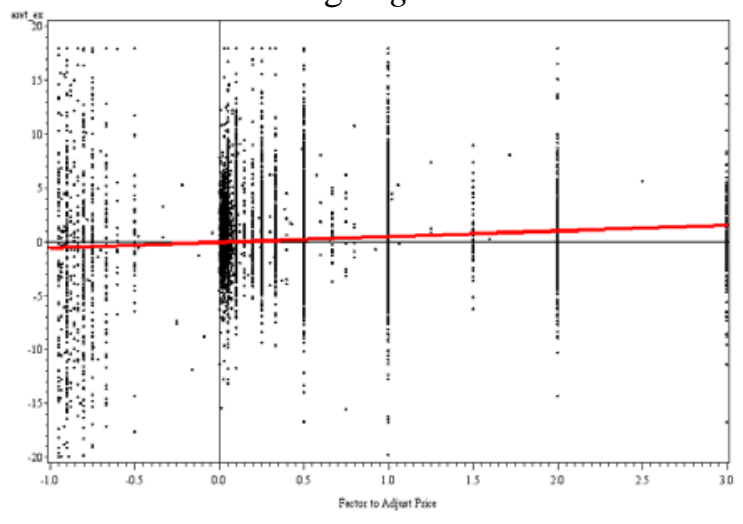



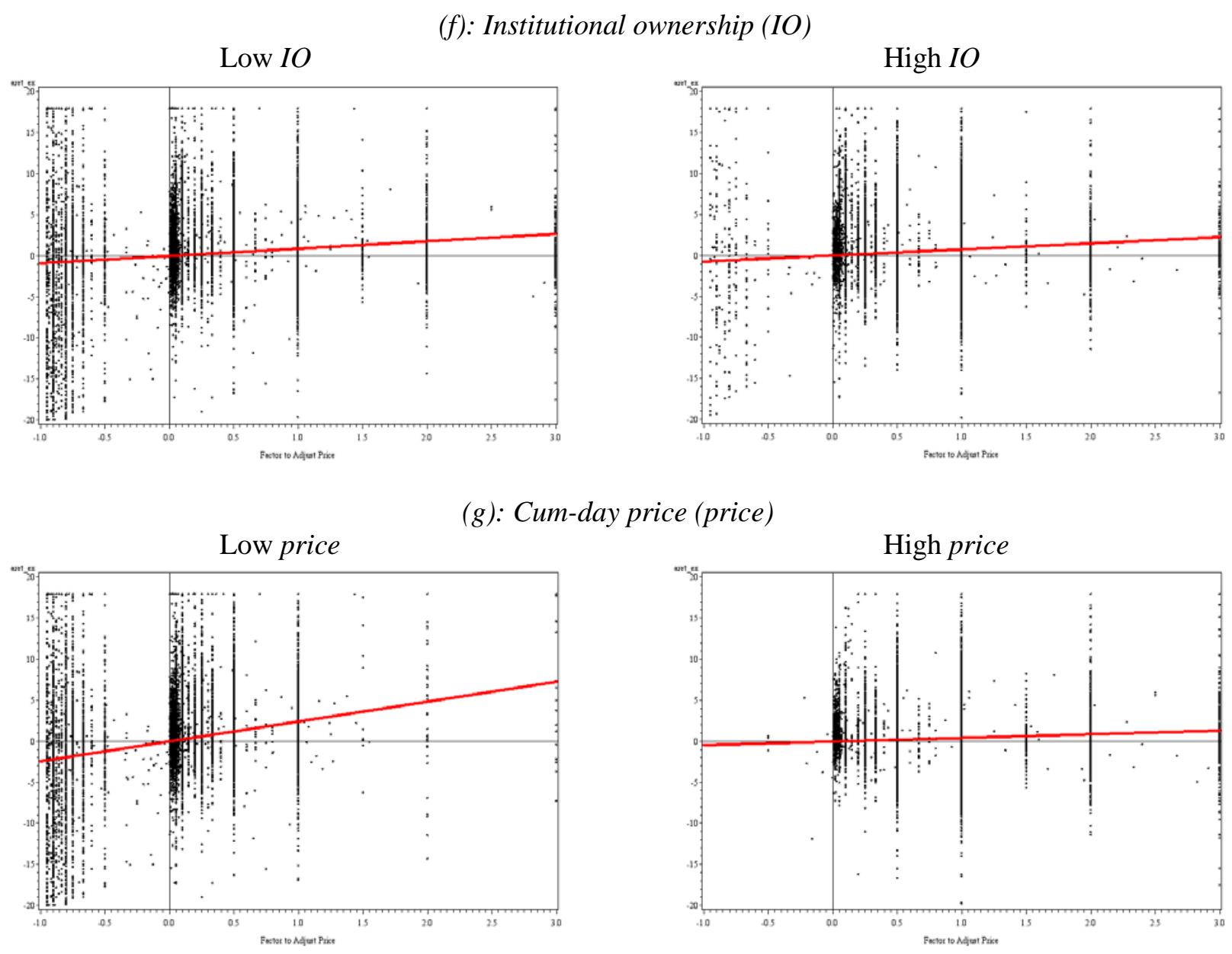

High price

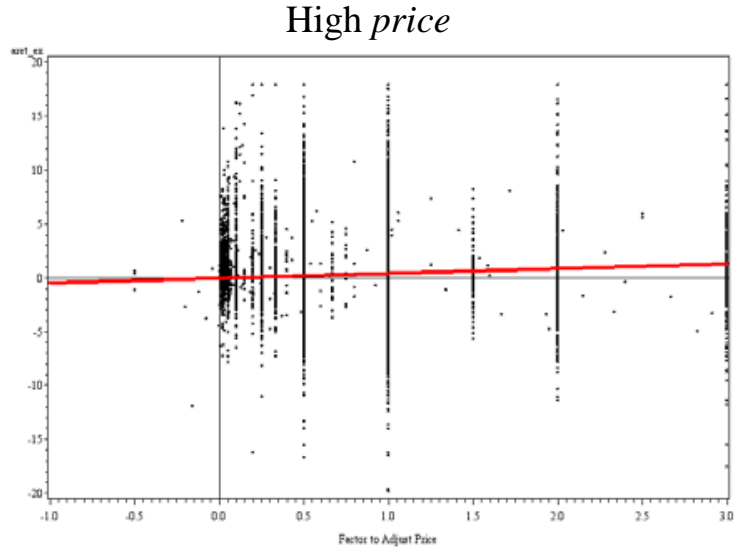

(h): Sentiment

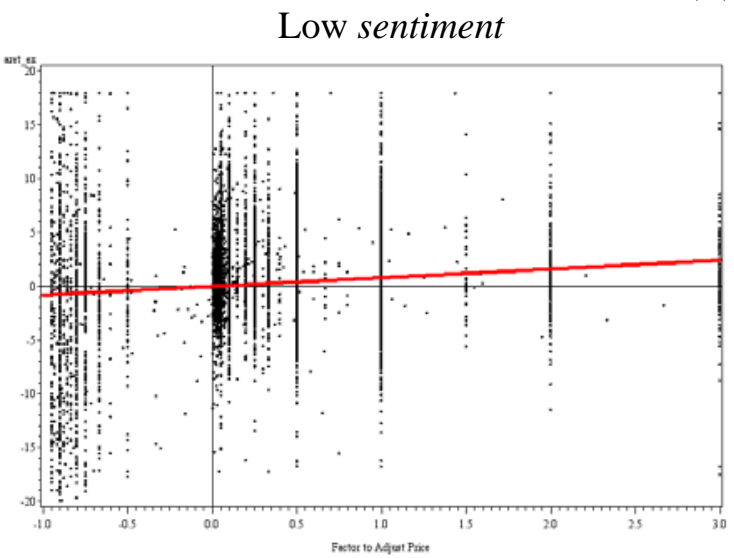

High sentiment

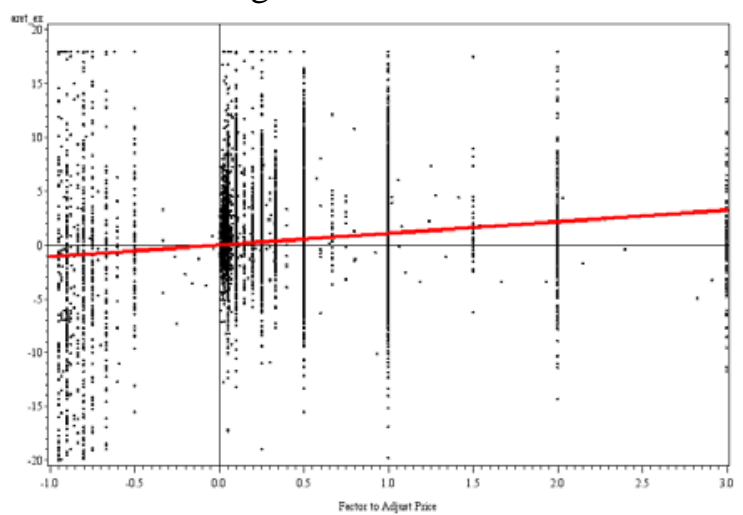




\section{Table 1: Descriptive Statistics of Event Returns}

We report the descriptive statistics of the event returns by type of the stock distribution event. Abnormal returns are raw returns adjusted for Carhart four factors, and the factor loadings are estimated using monthly returns over the 60-month period before the distribution month. We eliminate events with fewer than 24 months of returns in the estimation window and winsorize abnormal returns at the top and bottom one percentiles. We perform the $t$-test for the mean and the sign test for the median, and $*$, **, and *** indicate significance at the $10 \%, 5 \%$, and $1 \%$ levels, respectively.

\begin{tabular}{|c|c|c|c|}
\hline Type of event & $\mathrm{N}$ & Mean & Median \\
\hline \multicolumn{4}{|c|}{ Panel A: Raw return on ex-distribution day } \\
\hline Stock dividend & 9,695 & $1.50 \% * * *$ & $1.00 \% * * *$ \\
\hline Split & 17,868 & $1.10 \% * * *$ & $0.64 \% * * *$ \\
\hline Reverse split & 3,044 & $-4.55 \% * * *$ & $-2.98 \% * * *$ \\
\hline \multicolumn{4}{|c|}{ Panel B: Abnormal return on ex-distribution day } \\
\hline Stock dividend & 8,008 & $1.41 \% * * *$ & $0.93 \% * * *$ \\
\hline Split & 15,152 & $0.92 \% * * *$ & $0.48 \% * * *$ \\
\hline Reverse split & 2,664 & $-4.13 \% * * *$ & $-2.59 \% * * *$ \\
\hline \multicolumn{4}{|c|}{ Panel C: Abnormal return on ex-distribution day after 2001} \\
\hline Stock dividend & 799 & $1.51 \% * * *$ & $1.11 \% * * *$ \\
\hline Split & 1,995 & $0.31 \% * * *$ & $0.06 \%$ \\
\hline Reverse split & 1,156 & $-1.99 \% * * *$ & $-0.83 \% * * *$ \\
\hline \multicolumn{4}{|c|}{ Panel D: Abnormal bid-to-bid return on ex-distribution day } \\
\hline Stock dividend & 2,950 & $1.47 \% * * *$ & $0.93 \% * * *$ \\
\hline Split & 7,588 & $0.47 \% * * *$ & $0.12 \% * * *$ \\
\hline Reverse split & 2,109 & $-4.69 \% * * *$ & $-2.59 \% * * *$ \\
\hline \multicolumn{4}{|c|}{ Panel E: Cumulative abnormal return in 20 trading days after ex-day } \\
\hline Stock dividend & 8,024 & $-0.86 \% * * *$ & $-1.13 \% * * *$ \\
\hline Split & 15,191 & $0.25 \% * * *$ & $0.01 \%$ \\
\hline Reverse split & 2,631 & $-3.91 \% * * *$ & $-3.27 \% * * *$ \\
\hline
\end{tabular}




\section{Table 2: Ex-Day Returns Sorted by Adjustment Factors}

We report the average raw returns and abnormal returns on the ex-day sorted by adjustment factors. The abnormal returns are raw returns adjusted for Carhart four factors, where the factor loadings are estimated using monthly returns over the 60-month period before the distribution month, and events with fewer than 24 months of returns are eliminated. We winsorize variables at the top and bottom one percentiles. We perform the $t$-test for the mean and the sign-test for the median, and $*, * *$, and $* * *$ indicate significance at the $10 \%, 5 \%$, and $1 \%$ levels, respectively.

\begin{tabular}{|c|c|c|c|c|c|c|}
\hline \multirow[b]{2}{*}{ Adjustment factor } & \multirow[b]{2}{*}{$\mathrm{N}$} & \multicolumn{2}{|c|}{ Raw returns } & \multirow[b]{2}{*}{$\mathrm{N}$} & \multicolumn{2}{|c|}{ Abnormal returns } \\
\hline & & Mean & Median & & Mean & Median \\
\hline$(-1,-0.9)$ & 440 & $-9.11 \% * * *$ & $-10.00 \% * * *$ & 382 & $-8.54 \% * * *$ & $-9.81 \% * * *$ \\
\hline-0.9 & 614 & $-5.50 \% * * *$ & $-4.39 \% * * *$ & 533 & $-5.11 \% * * *$ & $-4.06 \% * * *$ \\
\hline$(-0.9,-0.75)$ & 917 & $-4.20 \% * * *$ & $-3.01 \% * * *$ & 825 & $-3.87 \% * * *$ & $-2.70 \% * * *$ \\
\hline-0.75 & 459 & $-2.14 \% * * *$ & $-0.47 \% * * *$ & 407 & $-1.84 \% * * *$ & $-0.50 \% * *$ \\
\hline$(-0.75,-0.5)$ & 357 & $-3.22 \% * * *$ & $-2.11 \% * * *$ & 298 & $-2.81 \% * * *$ & $-1.95 \% * * *$ \\
\hline-0.5 & 202 & $-1.14 \% *$ & $-0.06 \% *$ & 171 & $-0.40 \%$ & $-0.53 \%$ \\
\hline$(-0.5,0)$ & 98 & $-2.52 \% * * *$ & $-1.05 \% * *$ & 85 & $-2.19 \% * * *$ & $-1.31 \% * * *$ \\
\hline$(0,0.05)$ & 3,236 & $0.87 \% * * *$ & $0.68 \% * * *$ & 2,680 & $0.83 \% * * *$ & $0.66 \% * * *$ \\
\hline 0.05 & 3,149 & $1.57 \% * * *$ & $1.22 \% * * *$ & 2,603 & $1.52 \% * * *$ & $1.19 \% * * *$ \\
\hline$(0.05,0.10)$ & 394 & $1.64 \% * * *$ & $1.00 \% * * *$ & 320 & $1.55 \% * * *$ & $0.89 \% * * *$ \\
\hline 0.1 & 2,202 & $2.05 \% * * *$ & $1.37 \% * * *$ & 1,831 & $1.87 \% * * *$ & $1.08 \% * * *$ \\
\hline$(0.10,0.25)$ & 665 & $2.43 \% * * *$ & $1.30 \% * * *$ & 531 & $2.25 \% * * *$ & $1.16 \% * * *$ \\
\hline 0.25 & 1,616 & $1.56 \% * * *$ & $0.93 \% * * *$ & 1,373 & $1.54 \% * * *$ & $0.88 \% * * *$ \\
\hline$(0.25,0.5)$ & 646 & $1.42 \% * * *$ & $0.90 \% * * *$ & 548 & $1.36 \% * * *$ & $0.90 \% * * *$ \\
\hline 0.5 & 5,510 & $1.28 \% * * *$ & $0.84 \% * * *$ & 4,656 & $1.09 \% * * *$ & $0.70 \% * * *$ \\
\hline$(0.5,1)$ & 106 & $0.95 \% *$ & $1.07 \% * * *$ & 92 & $0.71 \%$ & $0.68 \%$ \\
\hline 1 & 8,405 & $0.86 \% * * *$ & $0.45 \% * * *$ & 7,171 & $0.65 \% * * *$ & $0.28 \% * * *$ \\
\hline$(1,2)$ & 177 & $1.13 \% * * *$ & $0.62 \% * * *$ & 144 & $1.11 \% * * *$ & $0.48 \% * *$ \\
\hline 2 & 948 & $1.25 \% * * *$ & $0.51 \% * * *$ & 807 & $0.89 \% * * *$ & $0.35 \% * * *$ \\
\hline$(2,3]$ & 466 & $0.99 \% * * *$ & $0.48 \% * * *$ & 367 & $0.87 \% * * *$ & $0.30 \%$ \\
\hline
\end{tabular}




\section{Table 3: Correlation}

We report Pearson correlations among major variables. The ex-day abnormal return (aret_ex) is the raw return on the ex-day adjusted for Carhart four factors. The variable factor is the adjustment factor for stock distribution events, price is the cum-day stock price, ret_- $6 \mathrm{~m}$ is the cumulative return in a six-month period that ends before distribution, $\Delta$ turnover is the change in turnover ratio from cum-day to ex-day, Nasdaq is a dummy variable that equals one if the stock is traded on Nasdaq and zero otherwise, time is the time trend variable, spread is the bid-ask spread on ex-day, and reversal is the cumulative abnormal return over 20 trading days after the ex-day. We winsorize all variables at the top and bottom one percentiles. *, **, and *** indicate significance at the $10 \%, 5 \%$, and $1 \%$ levels, respectively.

\begin{tabular}{|c|c|c|c|c|c|c|c|c|c|}
\hline & aret_ex & factor & price & ret_-6m & Aturnover & Nasdaq & time & spread & reversal \\
\hline aret_ex & 1 & $0.16^{* * *}$ & $0.03 * * *$ & $0.15 * * *$ & $-0.05 * * *$ & -0.01 & $-0.05 * * *$ & $-0.15 * * *$ & $-0.05 * * *$ \\
\hline factor & $0.16^{* * *}$ & 1 & $0.65 * * *$ & $0.32 * * *$ & $-0.12 * * *$ & $-0.16^{* * *}$ & $-0.09 * * *$ & $-0.33 * * *$ & $0.07 * * *$ \\
\hline price & $0.03 * * *$ & $0.65 * * *$ & 1 & $0.24 * * *$ & $-0.10 * * *$ & $-0.24 * * *$ & $-0.12 * * *$ & $-0.35 * * *$ & $0.04 * * *$ \\
\hline ret_-6m & $0.15^{* * *}$ & $0.32 * * *$ & $0.24 * * *$ & 1 & $-0.08 * * *$ & $0.05 * * *$ & $0.04 * * *$ & $-0.22 * * *$ & $0.03 * * *$ \\
\hline Aturnover & $-0.05 * * *$ & $-0.12 * * *$ & $-0.10 * * *$ & $-0.08 * * *$ & 1 & -0.01 & $0.06^{* * *}$ & -0.01 & -0.01 \\
\hline Nasdaq & -0.01 & $-0.16 * * *$ & $-0.24 * * *$ & $0.05^{* * *}$ & -0.01 & 1 & $0.37 * * *$ & $0.25 * * *$ & $-0.02 * * *$ \\
\hline time & $-0.05 * * *$ & $-0.09 * * *$ & $-0.12 * * *$ & $0.04 * * *$ & $0.06 * * *$ & $0.37 * * *$ & 1 & $-0.04 * * *$ & $-0.02 * * *$ \\
\hline spread & $-0.15 * * *$ & $-0.33 * * *$ & $-0.35 * * *$ & $-0.22 * * *$ & -0.01 & $0.25 * * *$ & $-0.04 * * *$ & 1 & 0 \\
\hline reversal & $-0.05 * * *$ & $0.07 * * *$ & $0.04 * * *$ & $0.03 * * *$ & -0.01 & $-0.02 * * *$ & $-0.02 * * *$ & 0 & 1 \\
\hline
\end{tabular}




\section{Table 4: Regress Ex-Day Returns on Adjustment Factors}

We regress Carhart-four-factor adjusted abnormal returns in percentage on the ex-day on $f$, the logarithm of the adjustment factor plus one. Control variables include the logarithm of cum-day price (logprice), the cumulative return in percentage over the prior six months (ret_-6m), the change in turnover ratio in percentage from cum-day to ex-day (Aturnover), the Nasdaq indicator, the time trend (time), and the bid-ask spread (spread) on the ex-day. We winsorize variables that are not in the logarithm terms at the top and bottom one percentiles. We use standard errors clustered in two ways by both stock and ex-day. *, $* *$, and $* * *$ indicate significance at the $10 \%, 5 \%$, and $1 \%$ levels, respectively.

\begin{tabular}{|c|c|c|c|c|c|c|c|}
\hline & (1) & (2) & (3) & (4) & (5) & (6) & (7) \\
\hline Intercept & $\begin{array}{c}0.218^{* * *} \\
(4.90)\end{array}$ & $\begin{array}{c}1.308^{* * * *} \\
(6.80)\end{array}$ & $\begin{array}{c}1.250 * * * \\
(6.44)\end{array}$ & $\begin{array}{c}0.994^{* * *} \\
(4.72)\end{array}$ & $\begin{array}{c}0.702^{* * *} \\
(3.32)\end{array}$ & $\begin{array}{c}1.008^{* * *} \\
(4.05)\end{array}$ & $\begin{array}{c}2.168^{* * *} \\
(3.76)\end{array}$ \\
\hline$f$ & $\begin{array}{c}1.877 * * * \\
(21.61)\end{array}$ & $\begin{array}{c}2.506^{* * *} \\
(18.33)\end{array}$ & $\begin{array}{c}2.420 * * * \\
(17.52)\end{array}$ & $\begin{array}{c}2.285^{* * *} \\
(16.12)\end{array}$ & $\begin{array}{c}2.253^{* * *} \\
(15.88)\end{array}$ & $\begin{array}{c}2.243 * * * \\
(15.76)\end{array}$ & $\begin{array}{c}2.280 * * * \\
(10.64)\end{array}$ \\
\hline logprice & & $\begin{array}{c}-0.402 * * * \\
(6.08)\end{array}$ & $\begin{array}{c}-0.440 * * * \\
(6.59)\end{array}$ & $\begin{array}{c}-0.359 * * * \\
(5.03)\end{array}$ & $\begin{array}{c}-0.302 * * * \\
(4.23)\end{array}$ & $\begin{array}{c}-0.304 * * * \\
(4.25)\end{array}$ & $\begin{array}{c}-0.381 * * * \\
(2.96)\end{array}$ \\
\hline ret_-6m & & & $\begin{array}{c}0.729 * * * \\
(8.14)\end{array}$ & $\begin{array}{c}0.712^{* * *} \\
(7.48)\end{array}$ & $\begin{array}{c}0.659 * * * \\
(6.86)\end{array}$ & $\begin{array}{c}0.669 * * * \\
(6.95)\end{array}$ & $\begin{array}{c}0.634^{* * *} \\
(4.72)\end{array}$ \\
\hline Aturnover & & & & $\begin{array}{l}0.014 \\
(0.19)\end{array}$ & $\begin{array}{l}0.020 \\
(0.28)\end{array}$ & $\begin{array}{l}0.025 \\
(0.34)\end{array}$ & $\begin{array}{l}0.005 \\
(0.07)\end{array}$ \\
\hline Nasdaq & & & & & $\begin{array}{c}0.352 * * * \\
(4.65)\end{array}$ & $\begin{array}{c}0.424 * * * \\
(5.11)\end{array}$ & $\begin{array}{c}0.574 * * * \\
(5.35)\end{array}$ \\
\hline time & & & & & & $\begin{array}{c}-0.005^{* *} \\
(2.25)\end{array}$ & $\begin{array}{c}-0.016^{* * *} \\
(3.52)\end{array}$ \\
\hline spread & & & & & & & $\begin{array}{c}-6.430 * * * \\
(3.08)\end{array}$ \\
\hline $\mathrm{N}$ & 25,824 & 25,792 & 25,790 & 23,751 & 23,751 & 23,751 & 12,813 \\
\hline $\mathrm{R}^{2}$-adj & $7.93 \%$ & $8.21 \%$ & $8.60 \%$ & $8.50 \%$ & $8.58 \%$ & $8.60 \%$ & $9.50 \%$ \\
\hline
\end{tabular}




\section{Table 5: Subsample Tests by Event Type}

We regress Carhart-four-factor adjusted abnormal returns in percentage on the ex-day on $f$, the logarithm of the adjustment factor plus one, for each type of stock distribution events: stock dividend distributions, splits, and reverse splits. Control variables include the logarithm of cum-day price (logprice), the cumulative return in percentage over the prior six months (ret_-6m), the change in turnover ratio in percentage from cum-day to ex-day (Aturnover), the Nasdaq indicator, and the time trend (time). We winsorize variables that are not in the logarithm terms at the top and bottom one percentiles. We use standard errors clustered in two ways by both stock and ex-day. *, **, and *** indicate significance at the $10 \%, 5 \%$, and $1 \%$ levels, respectively.

\begin{tabular}{|c|c|c|c|}
\hline & (1) Stock Dividends & (2) Splits & (3) Reverse splits \\
\hline Intercept & $\begin{array}{c}1.563 * * * \\
(4.96)\end{array}$ & $\begin{array}{c}4.391^{* * *} \\
(15.29)\end{array}$ & $\begin{array}{c}-9.664 * * * \\
(6.65)\end{array}$ \\
\hline$f$ & $\begin{array}{c}8.417 * * * \\
(5.32)\end{array}$ & $\begin{array}{c}0.579 * * * \\
(2.99)\end{array}$ & $\begin{array}{c}1.445^{* * * *} \\
(3.64)\end{array}$ \\
\hline logprice & $\begin{array}{c}-0.245 * * * \\
(3.21)\end{array}$ & $\begin{array}{c}-1.028 * * * \\
(12.46)\end{array}$ & $\begin{array}{c}0.943^{* * *} \\
(4.14)\end{array}$ \\
\hline ret_-6m & $\begin{array}{c}0.522 * * * \\
\quad(3.19)\end{array}$ & $\begin{array}{c}0.629 * * * \\
(6.51)\end{array}$ & $\begin{array}{c}1.863^{* * *} \\
(4.69)\end{array}$ \\
\hline$\Delta$ turnover & $\begin{array}{l}0.242 \\
(1.24)\end{array}$ & $\begin{array}{c}0.413 * * * \\
(6.08)\end{array}$ & $\begin{array}{c}-0.487 * * * \\
(3.89)\end{array}$ \\
\hline Nasdaq & $\begin{array}{c}1.044^{* * *} \\
(7.71)\end{array}$ & $\begin{array}{l}0.298 * * * \\
(3.86)\end{array}$ & $\begin{array}{c}-0.410 \\
(0.84)\end{array}$ \\
\hline time & $\begin{array}{c}-0.008 * \\
(1.96)\end{array}$ & $\begin{array}{c}-0.006 * * * \\
(2.58)\end{array}$ & $\begin{array}{c}0.127 * * * \\
(7.40)\end{array}$ \\
\hline $\mathrm{N}$ & 7,052 & 14,072 & 2,627 \\
\hline $\mathrm{R}^{2}$-adj & $3.41 \%$ & $4.75 \%$ & $7.79 \%$ \\
\hline
\end{tabular}




\section{Table 6: Sub-Period Tests by Decimalization}

We divide the entire sample period into two sub-periods of before and after decimalization in 2001, and regress Carhart-four-factor adjusted abnormal returns in percentage on the ex-day on $f$, the logarithm of the adjustment factor plus one, in each sub-period. Panel A reports results for the full sample, and Panel B reports results for subsamples by event type. The variable Pre2002 is a dummy that takes value of one if the event year is before 2002 and zero otherwise. Control variables include the logarithm of cum-day price (logprice), the cumulative return in percentage over the prior six months (ret_-6m), the change in turnover ratio in percentage from cum-day to ex-day ( $\Delta$ turnover), the Nasdaq indicator, and the time trend (time). We winsorize variables that are not in the logarithm terms at the top and bottom one percentiles. We use standard errors clustered in two ways by both stock and ex-day. *, **, and *** indicate significance at the $10 \%, 5 \%$, and $1 \%$ levels, respectively.

\begin{tabular}{|c|c|c|c|}
\hline \multicolumn{4}{|c|}{ Panel A: Full sample } \\
\hline & (1) Pre2002 & (2) Post2002 & (3)Whole period \\
\hline Intercept & $\begin{array}{c}1.655^{* * * *} \\
(6.28)\end{array}$ & $\begin{array}{c}-7.613 * * * \\
(3.16)\end{array}$ & $\begin{array}{c}1.537 * * * \\
(4.63)\end{array}$ \\
\hline$f$ & $\begin{array}{c}2.961^{* * *} \\
(18.85)\end{array}$ & $\begin{array}{c}0.829 * * * \\
(2.67)\end{array}$ & $\begin{array}{c}1.562^{* * *} \\
(8.75)\end{array}$ \\
\hline$f \times$ Pre2002 & & & $\begin{array}{c}1.188 * * * \\
(6.58)\end{array}$ \\
\hline Pre2002 & & & $\begin{array}{c}-0.323^{* *} \\
(2.47)\end{array}$ \\
\hline logprice & $\begin{array}{c}-0.485 * * * \\
(6.61)\end{array}$ & $\begin{array}{l}0.176 \\
(0.96)\end{array}$ & $\begin{array}{c}-0.351 * * * \\
(5.00)\end{array}$ \\
\hline ret_-6m & $\begin{array}{c}0.690 * * * \\
(6.95)\end{array}$ & $\begin{array}{c}0.787 * * \\
(2.42)\end{array}$ & $\begin{array}{c}0.677^{* * * *} \\
(6.96)\end{array}$ \\
\hline Aturnover & $\begin{array}{l}0.080 \\
(0.85)\end{array}$ & $\begin{array}{c}-0.143 \\
(1.36)\end{array}$ & $\begin{array}{c}-0.019 \\
(0.26)\end{array}$ \\
\hline Nasdaq & $\begin{array}{c}0.351^{* * *} \\
(3.94)\end{array}$ & $\begin{array}{c}1.301^{* * *} \\
(5.91)\end{array}$ & $\begin{array}{c}0.475^{* * *} \\
(5.71)\end{array}$ \\
\hline time & $\begin{array}{c}-0.010 * * * \\
(3.59)\end{array}$ & $\begin{array}{c}0.079 * * * \\
(2.72)\end{array}$ & $\begin{array}{c}-0.010 * * * \\
(3.39)\end{array}$ \\
\hline $\mathrm{N}$ & 19,802 & 3,949 & 23,751 \\
\hline $\mathrm{R}^{2}$-adj & $10.57 \%$ & $5.49 \%$ & $9.35 \%$ \\
\hline
\end{tabular}




\begin{tabular}{|c|c|c|c|c|c|c|c|c|c|}
\hline \multicolumn{10}{|c|}{ Panel B: Subsamples by event type } \\
\hline & \multicolumn{3}{|c|}{ Stock Dividends } & \multicolumn{3}{|c|}{ Splits } & \multicolumn{3}{|c|}{ Reverse Splits } \\
\hline & Pre2002 & Post2002 & Whole period & Pre2002 & Post2002 & Whole period & Pre2002 & Post2002 & Whole period \\
\hline Intercept & (3.98) & $(0.33)$ & $(2.37)$ & $(12.01)$ & $(2.78)$ & (7.93) & $(1.06)$ & $(3.44)$ & $(1.02)$ \\
\hline \multirow[t]{2}{*}{$f$} & $8.371^{* * *}$ & $8.652 *$ & $9.256 * *$ & $0.556 * *$ & $0.736^{*}$ & $1.006^{* * *}$ & $2.185^{* * *}$ & $1.055^{*}$ & $1.172^{* *}$ \\
\hline & $(4.90)$ & $(1.78)$ & $(2.07)$ & $(2.54)$ & $(1.73)$ & (3.23) & $(4.22)$ & $(1.72)$ & $(2.07)$ \\
\hline \multirow[t]{2}{*}{ Pre2002 } & & & 0.202 & & & $0.761 * * *$ & & & -1.816 \\
\hline & & & $(0.59)$ & & & (3.27) & & & $(1.43)$ \\
\hline \multirow[t]{2}{*}{ logprice } & $-0.215 * * *$ & -0.324 & $-0.237 * * *$ & $-1.013 * * *$ & $-0.766^{* * *}$ & $-0.991 * * *$ & 0.214 & $1.260 * * *$ & $0.800 * * *$ \\
\hline & $(2.62)$ & $(1.45)$ & (3.07) & (11.45) & (2.73) & (11.82) & $(0.64)$ & $(4.16)$ & (3.51) \\
\hline \multirow[t]{2}{*}{ ret_-6m } & $0.435 * *$ & $1.246^{* *}$ & $0.519 * * *$ & $0.583 * * *$ & $0.704^{*}$ & $0.595^{* * *}$ & $3.042 * * *$ & 0.587 & $1.924 * * *$ \\
\hline & $(2.44)$ & $(2.46)$ & (3.18) & (5.88) & (1.95) & (6.16) & (5.81) & $(1.00)$ & (4.79) \\
\hline \multirow[t]{2}{*}{ time } & -0.005 & -0.006 & -0.006 & 0.000 & -0.025 & 0.000 & 0.042 & $0.269 * * *$ & 0.042 \\
\hline & $(1.05)$ & $(0.13)$ & $(1.31)$ & $(0.03)$ & $(1.05)$ & $(0.06)$ & (1.45) & (3.29) & $(1.60)$ \\
\hline $\mathrm{N}$ & 6,253 & 799 & 7,052 & 12,077 & 1,995 & 14,072 & 1,472 & 1,155 & 2,627 \\
\hline $\mathrm{R}^{2}$-adj & $3.20 \%$ & $5.54 \%$ & $3.39 \%$ & $4.93 \%$ & $3.51 \%$ & $4.89 \%$ & $7.93 \%$ & $6.40 \%$ & $8.70 \%$ \\
\hline
\end{tabular}




\section{Table 7: Moderating Effect of Anchoring Propensity}

We regress Carhart-four-factor adjusted abnormal returns in percentage on the ex-day on $f$, the logarithm of the adjustment factor plus one, and its interaction with investors' anchoring propensity $(\gamma)$. Anchoring propensity is measured by a group of variables, including the salience of events (salience), the number of concurring earnings announcements on ex-day (\#news), the idiosyncratic volatility (idiovol), the bid-ask spread on ex-day (spread), the institutional ownership (IO), the logarithm of the cum-day price (logprice) and the firm age (logage), and the market sentiment in the previous month (sentiment). Control variables include the logarithm of cum-day price (logprice), the cumulative return in percentage over the prior six months (ret_-6m), the change in turnover ratio in percentage from cum-day to ex-day ( $\Delta$ turnover), the Nasdaq indicator, and the time trend (time). We winsorize variables that are not in the logarithm terms at the top and bottom one percentiles. We use standard errors clustered in two ways by both stock and ex-day. *, **, and *** indicate significance at the $10 \%, 5 \%$, and $1 \%$ levels, respectively.

\begin{tabular}{|c|c|c|c|c|c|c|c|c|}
\hline$\gamma=$ & (1) salience & (2) \#news & (3) spread & (4) idiovol & (5) logage & (6) $\mathrm{IO}$ & (7) logprice & (8) sentiment \\
\hline Intercept & $\begin{array}{c}0.899 * * * \\
(3.61)\end{array}$ & $\begin{array}{c}1.275^{* * *} \\
(4.76)\end{array}$ & $\begin{array}{l}0.600 \\
(1.06)\end{array}$ & $\begin{array}{c}1.909^{* * *} \\
(8.13)\end{array}$ & $\begin{array}{c}1.090^{* * *} \\
(3.98)\end{array}$ & $\begin{array}{l}0.144 \\
(0.52)\end{array}$ & $\begin{array}{c}1.458^{* * *} \\
(6.45)\end{array}$ & $\begin{array}{c}1.458^{* * * *} \\
(5.57)\end{array}$ \\
\hline$f$ & $\begin{array}{c}2.967 * * * \\
(11.74)\end{array}$ & $\begin{array}{c}1.538^{* * *} \\
(7.06)\end{array}$ & $\begin{array}{c}1.187 * * * \\
(5.56)\end{array}$ & $\begin{array}{c}1.198^{* * *} \\
(8.68)\end{array}$ & $\begin{array}{c}4.139 * * * \\
(13.06)\end{array}$ & $\begin{array}{c}2.345^{* * *} \\
(16.36)\end{array}$ & $\begin{array}{c}2.490 * * * \\
(17.99)\end{array}$ & $\begin{array}{c}2.348^{* * *} \\
(14.75)\end{array}$ \\
\hline$\gamma \times f$ & $\begin{array}{c}-0.849 * * * \\
(3.38)\end{array}$ & $\begin{array}{c}0.124 * * * \\
(4.06)\end{array}$ & $\begin{array}{c}11.773 * * * \\
(8.53)\end{array}$ & $\begin{array}{c}1.786^{* * *} \\
(6.72)\end{array}$ & $\begin{array}{c}-0.836 * * * \\
(6.98)\end{array}$ & $\begin{array}{c}-4.099 * * * \\
(6.58)\end{array}$ & $\begin{array}{c}-0.628^{* * *} \\
(16.88)\end{array}$ & $\begin{array}{c}0.525^{* * *} \\
(4.22)\end{array}$ \\
\hline$\gamma$ & $\begin{array}{c}-1.648^{* * *} \\
(18.46)\end{array}$ & $\begin{array}{c}-0.019 \\
(1.00)\end{array}$ & $\begin{array}{c}7.283^{* * *} \\
(3.41)\end{array}$ & $\begin{array}{c}-0.989 * \\
(1.76)\end{array}$ & $\begin{array}{c}-0.011 \\
(0.17)\end{array}$ & $\begin{array}{l}0.566 \\
(1.46)\end{array}$ & & $\begin{array}{c}-0.171^{* * *} \\
(3.07)\end{array}$ \\
\hline logprice & $\begin{array}{c}-0.193 * * * \\
(2.71)\end{array}$ & $\begin{array}{c}-0.298 * * * \\
(4.16)\end{array}$ & $\begin{array}{l}-0.067 \\
(0.54)\end{array}$ & $\begin{array}{c}-0.436^{* * * *} \\
(6.61)\end{array}$ & $\begin{array}{c}-0.286^{* * * *} \\
(3.97)\end{array}$ & $\begin{array}{c}-0.189 * * * \\
(2.62)\end{array}$ & $\begin{array}{c}-0.243 * * * \\
(3.70)\end{array}$ & $\begin{array}{c}-0.380^{* * *} \\
(4.72)\end{array}$ \\
\hline ret_-6m & $\begin{array}{c}0.846^{* * * *} \\
(8.80)\end{array}$ & $\begin{array}{c}0.644^{* * *} \\
(6.72)\end{array}$ & $\begin{array}{c}0.652^{* * *} \\
(4.91)\end{array}$ & $\begin{array}{c}0.751^{* * * *} \\
(7.02)\end{array}$ & $\begin{array}{c}0.568 * * * \\
(5.80)\end{array}$ & $\begin{array}{c}0.650 * * * \\
(6.82)\end{array}$ & $\begin{array}{c}0.738 * * * \\
(7.81)\end{array}$ & $\begin{array}{c}0.683 * * * \\
(6.87)\end{array}$ \\
\hline Aturnover & $\begin{array}{l}0.037 \\
(0.51)\end{array}$ & $\begin{array}{l}0.040 \\
(0.55)\end{array}$ & $\begin{array}{c}-0.048 \\
(0.64)\end{array}$ & $\begin{array}{l}0.043 \\
(0.66)\end{array}$ & $\begin{array}{l}0.019 \\
(0.26)\end{array}$ & $\begin{array}{l}0.000 \\
(0.00)\end{array}$ & $\begin{array}{l}0.048 \\
(0.74)\end{array}$ & $\begin{array}{l}0.023 \\
(0.31)\end{array}$ \\
\hline Nasdaq & $\begin{array}{c}0.363 * * * \\
(4.53)\end{array}$ & $\begin{array}{c}0.429 * * * \\
(5.18)\end{array}$ & $\begin{array}{c}0.472^{* * *} \\
(4.47)\end{array}$ & $\begin{array}{c}0.504^{* * *} \\
(6.28)\end{array}$ & $\begin{array}{c}0.319 * * * \\
(3.74)\end{array}$ & $\begin{array}{c}0.379 * * * \\
(4.64)\end{array}$ & $\begin{array}{c}0.444^{* * *} \\
(5.73)\end{array}$ & $\begin{array}{c}0.451^{* * *} \\
(5.25)\end{array}$ \\
\hline time & $\begin{array}{c}0.007 * * * \\
(2.99)\end{array}$ & $\begin{array}{c}-0.008^{* *} \\
(2.26)\end{array}$ & $\begin{array}{c}-0.009^{* *} \\
(2.02)\end{array}$ & $\begin{array}{c}-0.006^{* * *} \\
(2.67)\end{array}$ & $\begin{array}{c}-0.004^{*} \\
(1.76)\end{array}$ & $\begin{array}{c}0.007 * * \\
(2.36)\end{array}$ & $\begin{array}{c}-0.001 \\
(0.36)\end{array}$ & $\begin{array}{c}-0.009^{* * *} \\
(2.79)\end{array}$ \\
\hline $\mathrm{N}$ & 23,751 & 23,751 & 12,813 & 23,731 & 23,751 & 23,751 & 23,751 & 20,974 \\
\hline $\mathrm{R}^{2}$-adj & $10.94 \%$ & $8.84 \%$ & $11.51 \%$ & $12.38 \%$ & $9.44 \%$ & $9.50 \%$ & $12.54 \%$ & $9.69 \%$ \\
\hline
\end{tabular}




\section{Table 8: Moderating Effect of Investor Sophistication Using Account-Level Data}

We regress Carhart-four-factor adjusted abnormal returns in percentage on the ex-day on $f$, the logarithm of the adjustment factor plus one, and its interaction with four measures of investors' anchoring propensity $(\gamma)$, constructed based on the account-level data from a U.S. discount brokerage house from 1991 to 1996. ExcessWt is a dummy variable that equals one if the average weight of the event stock in the portfolio of the brokerage investors in excess of its weight in the market portfolio is greater than the sample median and zero otherwise. Equity is the logarithm of the average equity position of the brokerage investors holding the stock at the end of month before the event. InvExp1 is the investment experience of the brokerage investors trading the event stock measured by the average number of years since the stock account is opened. InvExp2 is the average number of trades that investors have executed before trading the event stock. Control variables include the logarithm of cum-day price (logprice), the cumulative return in percentage over the prior six months $\left(\right.$ ret_$\left._{-}-6 m\right)$, the change in turnover ratio in percentage from cum-day to ex-day ( $\Delta$ turnover), the Nasdaq indicator, and the time trend (time). We winsorize variables that are not in the logarithm terms at the top and bottom one percentiles. We use standard errors clustered in two ways by both stock and ex-day. *, **, and *** indicate significance at the $10 \%, 5 \%$, and $1 \%$ levels, respectively.

\begin{tabular}{lccccc}
\hline$\gamma=$ & (1) Benchmark & $(2)$ ExcessWt & $(3)$ Equity & $(4)$ InvExp1 & $(5)$ InvExp2 \\
\hline Intercept & $0.052^{* * *}$ & $0.060^{* * *}$ & 0.017 & $0.037^{* * *}$ & $0.053^{* * *}$ \\
$f$ & $(7.71)$ & $(8.04)$ & $(0.73)$ & $(3.69)$ & $(7.83)$ \\
& $0.028^{* * *}$ & $0.007^{*}$ & $0.180^{* * *}$ & $0.054^{* * *}$ & $0.030 * * *$ \\
$\gamma \times f$ & $(3.35)$ & $(1.41)$ & $(3.01)$ & $(3.11)$ & $(3.57)$ \\
& & $0.036^{* * *}$ & $-0.013^{* * *}$ & $-0.004^{*}$ & $-0.011^{* *}$ \\
$\gamma$ & & $(3.64)$ & $(2.74)$ & $(1.85)$ & $(2.25)$ \\
& & $-0.011^{* * *}$ & 0.003 & $0.000^{* *}$ & $0.008^{* *}$ \\
logprice & & $(-2.78)$ & $(1.46)$ & $(2.16)$ & $(2.42)$ \\
& $-0.016^{* * *}$ & $-0.016^{* * *}$ & $-0.015^{* * *}$ & $-0.016^{* * *}$ & $-0.017 * * *$ \\
$\Delta t u r n o v e r$ & $(7.36)$ & $(6.85)$ & $(6.29)$ & $(6.55)$ & $(7.62)$ \\
& -0.225 & -0.240 & -0.135 & -0.199 & -0.227 \\
ret_-6m & $(1.38)$ & $(1.53)$ & $(0.87)$ & $(1.17)$ & $(1.36)$ \\
& $0.009^{* * *}$ & $0.007^{* *}$ & $0.007 * *$ & $0.009 * * *$ & $0.009 * * *$ \\
Nasdaq & $(3.12)$ & $(2.56)$ & $(2.48)$ & $(3.27)$ & $(3.04)$ \\
& $0.004^{* *}$ & 0.003 & 0.002 & 0.002 & $0.004 * *$ \\
time & $(2.00)$ & $(1.50)$ & $(0.95)$ & $(1.24)$ & $(2.12)$ \\
& -0.000 & -0.000 & -0.001 & -0.001 & -0.000 \\
\hline $\mathrm{N}$ & $(0.65)$ & $(0.69)$ & $(0.62)$ & $(1.08)$ & $(0.80)$ \\
$\mathrm{R}^{2}$-adj & 2,236 & 2,236 & 2,108 & 2,111 & 2,236 \\
& $5.98 \%$ & $7.78 \%$ & $6.90 \%$ & $6.06 \%$ & $6.34 \%$ \\
\hline
\end{tabular}




\section{Table 9: Post-Event Returns}

We regress the cumulative Carhart-four-factor adjusted abnormal returns in percentage over 20 trading days following the ex-day (car_post) on the ex-day abnormal returns in percentage (aret_ex). Regression results for the full sample and the three event types are reported separately. Control variables include the logarithm of cum-day price (logprice), the cumulative return in percentage over the prior six months (ret_-6m), the change in turnover ratio in percentage from cum-day to ex-day (Aturnover), the Nasdaq indicator, and the time trend (time). We winsorize variables that are not in the logarithm terms at the top and bottom one percentiles. We use standard errors clustered in two ways by both stock and ex-day. *, **, and $* * *$ indicate significance at the $10 \%, 5 \%$, and $1 \%$ levels, respectively.

\begin{tabular}{lcccc}
\hline & (1) Full sample & (2) Stock dividend & (3) Splits & (4) Reverse split \\
\hline Intercept & $-3.103^{* * *}$ & -0.322 & $1.999^{* * *}$ & 0.569 \\
& $(7.96)$ & $(0.49)$ & $(2.66)$ & $(0.26)$ \\
aret_ex & $-0.181^{* * *}$ & $-0.290^{* * *}$ & $-0.276^{* * *}$ & $-0.150^{* * *}$ \\
& $(8.13)$ & $(7.39)$ & $(8.48)$ & $(3.92)$ \\
logprice & $0.849^{* * *}$ & $-0.271^{*}$ & $-0.311^{*}$ & $0.821^{* * *}$ \\
& $(10.29)$ & $(1.69)$ & $(1.90)$ & $(2.62)$ \\
ret_-6m & 0.055 & $-0.848^{*}$ & 0.057 & 0.268 \\
& $(0.24)$ & $(1.83)$ & $(0.20)$ & $(0.37)$ \\
Aturnover & $0.447^{* * *}$ & $1.788^{* * *}$ & $0.637 * * *$ & 0.002 \\
& $(3.92)$ & $(4.48)$ & $(4.29)$ & $(0.01)$ \\
Nasdaq & 0.273 & $0.718^{* *}$ & $0.429 *$ & $-1.926^{* *}$ \\
& $(1.46)$ & $(2.32)$ & $(1.91)$ & $(2.08)$ \\
time & -0.001 & 0.007 & -0.009 & -0.046 \\
& $(0.13)$ & $(0.95)$ & $(1.49)$ & $(1.60)$ \\
\hline $\mathrm{N}$ & 23,679 & 7,048 & 14,067 & 2,564 \\
$\mathrm{R}^{2}$-adj & $1.56 \%$ & $2.32 \%$ & $1.18 \%$ & $1.18 \%$ \\
\hline
\end{tabular}




\section{Table 10: Robustness: Microstructure Effects}

We regress the Carhart-four-factor adjusted abnormal returns in percentage on the ex-day on $f$, the logarithm of the adjustment factor plus one, controlling for additional microstructure variables. The dependent variable is the abnormal return in Columns (1) and (3), and the bid-to-bid abnormal return in Column (2). Location parameter is (close price-bid)/(ask-bid) on ex-day. The tick size is 1/8 before 23 June 1997, 1/16 from 24 June 1997 to 26 August 2000, and 0.01 after 29 January 2001 for NYSE stocks. The rational ex-day price is the cum-day price/(1+factor) and then rounded up to the nearest tick. Rounding return is the rounding error scaled by the rational ex-day price. Control variables include the logarithm of cum-day price (logprice), the cumulative return in percentage over the prior six months (ret_-6m), the change in turnover ratio in percentage from cum-day to ex-day ( $\Delta$ turnover), the Nasdaq indicator, and the time trend (time). We winsorize variables that are not in the logarithm terms at the top and bottom one percentiles. We use standard errors clustered in two ways by both stock and ex-day. *, **, and $* * *$ indicate significance at the $10 \%, 5 \%$, and $1 \%$ levels, respectively.

\begin{tabular}{lccc}
\hline & $(1)$ & (2) bid-to-bid return & $(3)$ \\
\hline Intercept & $-0.839^{* *}$ & $-1.906^{* * *}$ & -0.379 \\
& $(2.26)$ & $(5.25)$ & $(1.06)$ \\
& $2.296^{* * *}$ & $0.969^{* * *}$ & $0.846^{* * *}$ \\
logprice & $(10.52)$ & $(4.66)$ & $(5.07)$ \\
& $-0.315^{* * *}$ & $0.487^{* * *}$ & 0.043 \\
ret_-6m & $(2.62)$ & $(4.20)$ & $(0.45)$ \\
& $0.764^{* * *}$ & $0.967^{* * *}$ & $0.879 * * *$ \\
Aturnover & $(5.19)$ & $(6.51)$ & $(7.23)$ \\
& $-0.208^{* * *}$ & $-0.102^{*}$ & $-0.148^{*}$ \\
Nasdaq & $(3.55)$ & $(1.90)$ & $(1.83)$ \\
& $0.423^{* * *}$ & $0.272^{* *}$ & \\
time & $(3.89)$ & $(2.50)$ & \\
& $-0.010^{* *}$ & $-0.008^{*}$ & $-0.007 * * *$ \\
location parameter & $(2.12)$ & $(1.65)$ & $(2.73)$ \\
& $3.095^{* * *}$ & & \\
rounding return & $(21.02)$ & & $1.050^{* * *}$ \\
& & & $(4.59)$ \\
\hline $\mathrm{N}$ & & 11,611 \\
$\mathrm{R}^{2}$-adj & 11,281 & $9.54 \%$ & $3.50 \%$ \\
\hline
\end{tabular}

